\title{
LA-UR-20-30089
}

Approved for public release; distribution is unlimited.

Title:

Author(s):

Intended for:

Issued:
Beyond the Moon

Carr, Alan Brady

Historical talk of general interest 
Disclaimer:

Los Alamos National Laboratory, an affirmative action/equal opportunity employer, is operated by Triad National Security, LLC for the National Nuclear Security Administration of U.S. Department of Energy under contract 89233218CNA000001. By approving this article, the publisher recognizes that the U.S. Government retains nonexclusive, royalty-free license to publish or reproduce the published form of this contribution, or to allow others to do so, for U.S. Government purposes. Los Alamos National Laboratory requests that the publisher identify this article as work performed under the auspices of the U.S. Department of Energy. Los Alamos National Laboratory strongly supports academic freedom and a researcher's right to publish; as an institution, however, the Laboratory does not endorse the viewpoint of a publication or guarantee its technical correctness. 


\section{Beyond the Moon}

A historical talk addressing the Los Alamos Rover program in which scientists worked on nuclear powered rocket engines. The talk is by historian Alan Carr, this talk is a refresh of an older talk on the subject with the same title. 

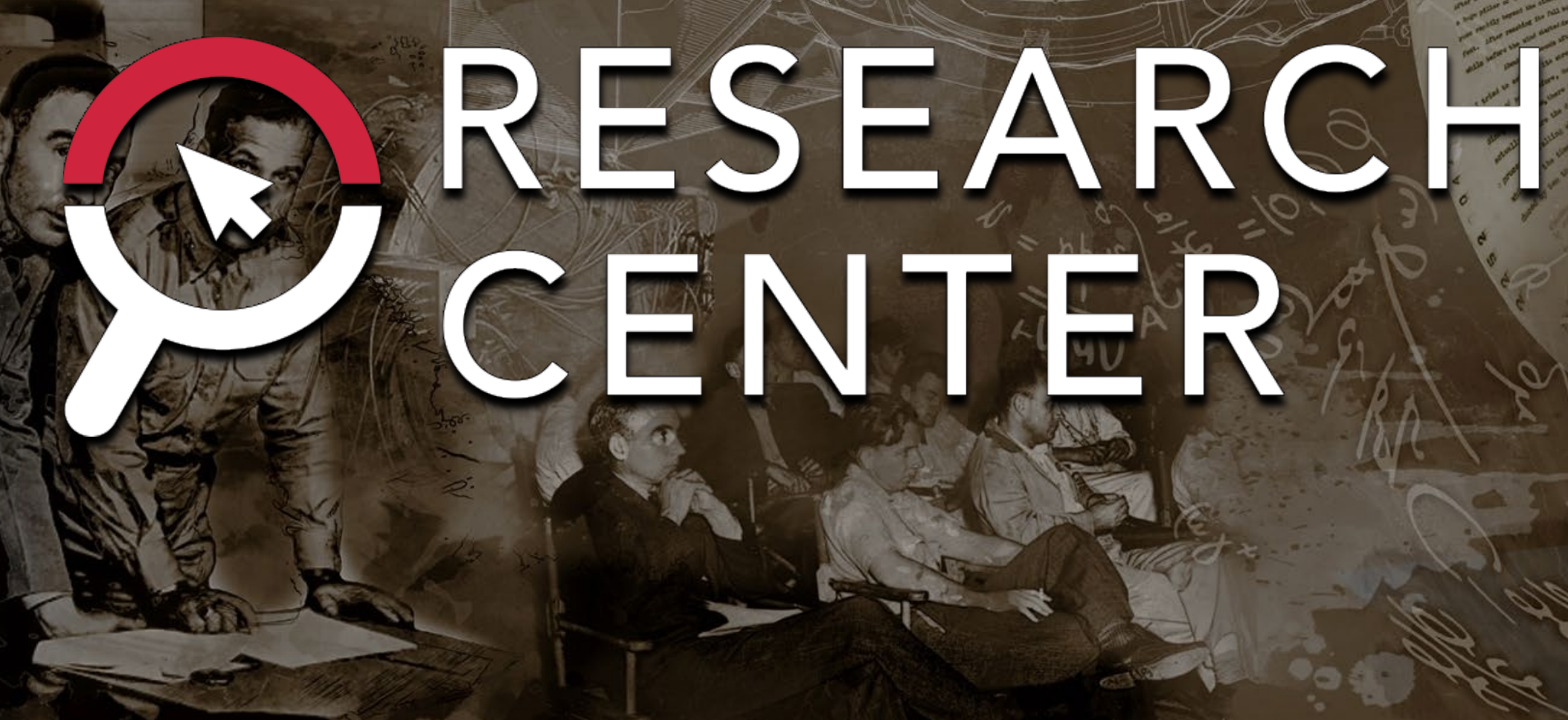


\section{Beyond the Moon}

The Story of the Rover Program 1955 to 1973

NATIONAL SECURITY

ReSEARCh CENTER
Alan B. Carr

NSRC Senior Historian WRS-SIS Program Manager 
Twenty years ago, the scene you're-about to see belonged only in the notebook of the science fiction whriter. perhaps under the heading, "rémote possibility." "Büt then, in 1945, the awe some power of the atom's nucleus was revealed for all the world to see. And after that,

NOTHING SEEMS IMPOSSIBLE. 


\section{${ }_{\text {PRoureat Talks Start with Great Org Charts }}^{05}$}

\section{MAIN GATE}

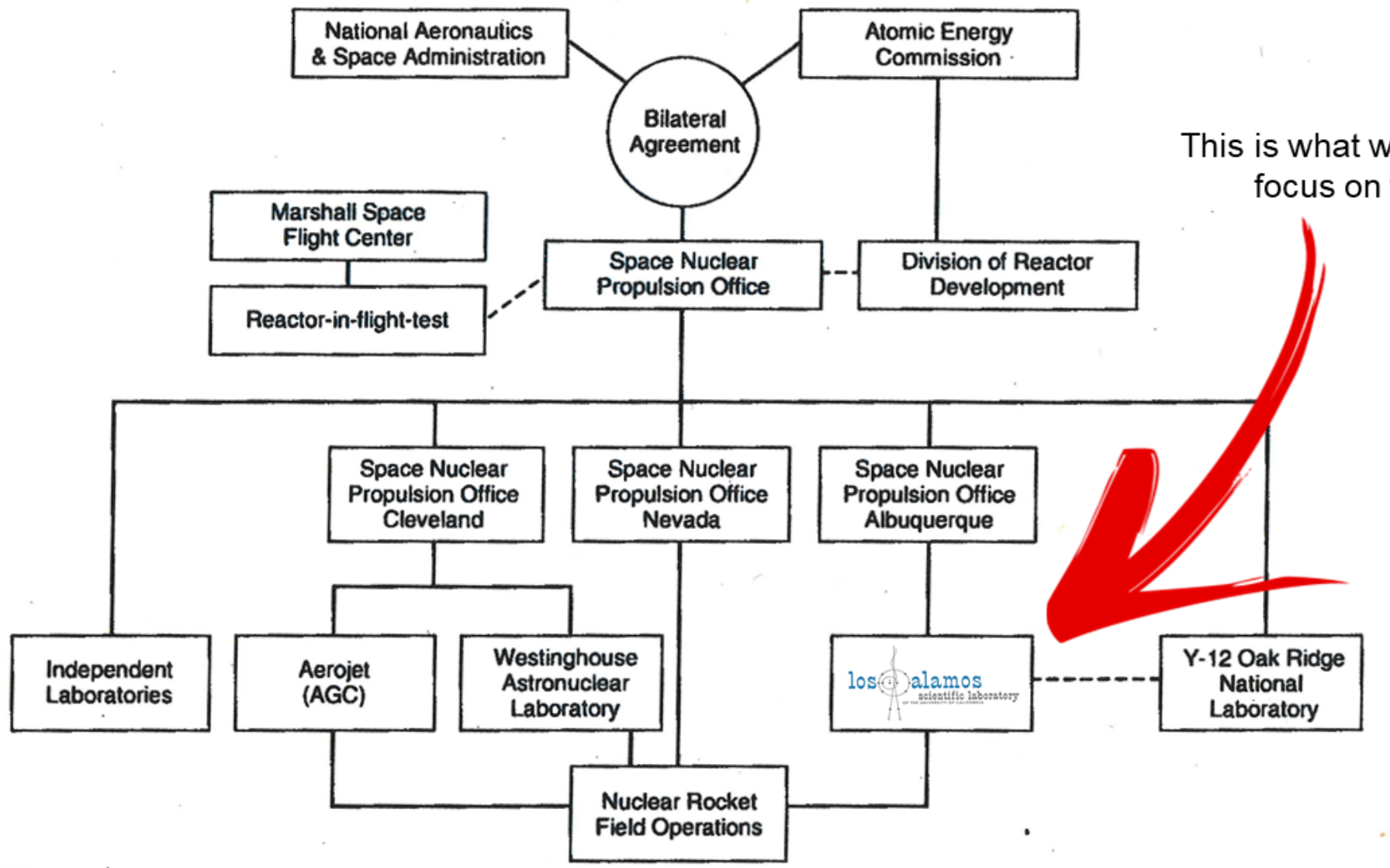




\section{.05 AlWhy a nuclear rocket?}

"The answer, of course, is the specific impulse [I-sp] possible with hydrogen as the propellant! The I-sp from hydrogen is about three times that achievable from the most energetic chemical propellant. I-sp is a measure of the efficiency of a rocket engine. Simplistically, it can be considered as the ratio of weight to perform a specific mission - the weight to perform an Earth orbit to moon orbit for a nuclear rocket is about one-third of the weight for a chemical rocket for the same mission. It can also be considered as the pounds of thrust per pound of propellant."

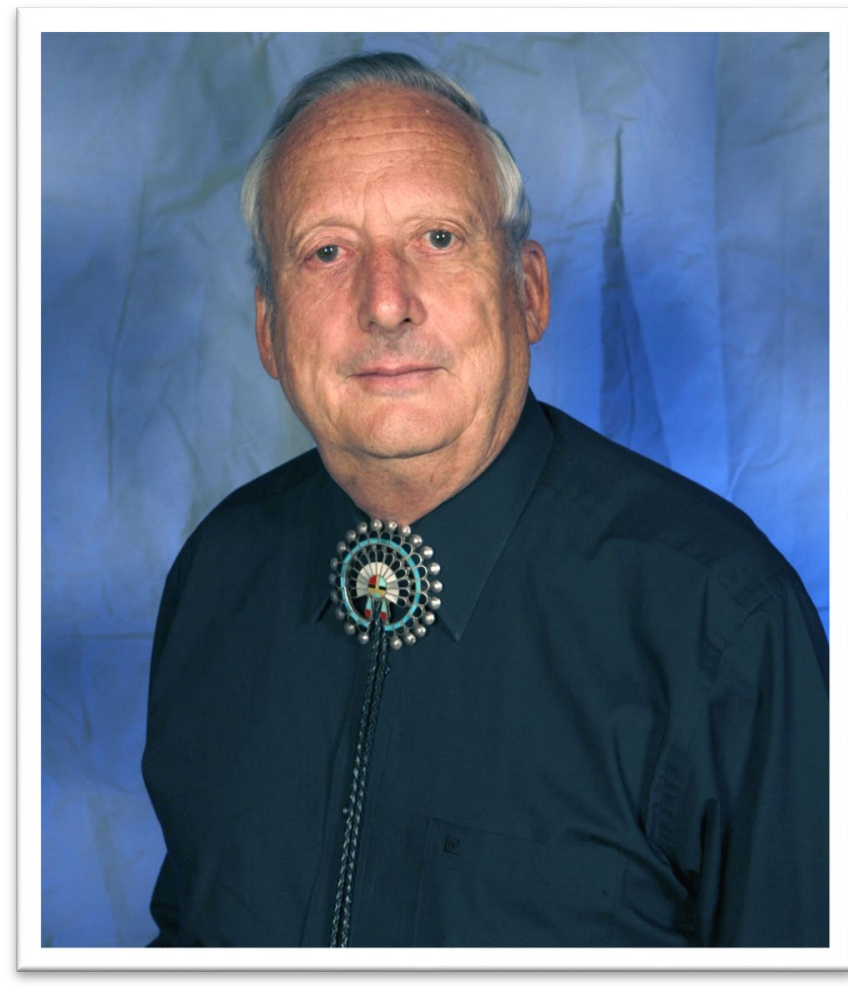

Dick Malenfant Rover Program Veteran 
- Robert Goddard first proposed atomic space travel as a college student in 1906-1907

- In 1916, Goddard concluded there was no practical method for controlling atomic disintegration of radium ions

- In the years leading up to World War II, speculation continued in Europe

- Although work nearly ceased during the war, the postwar years saw concrete (if not practical) propulsion designs

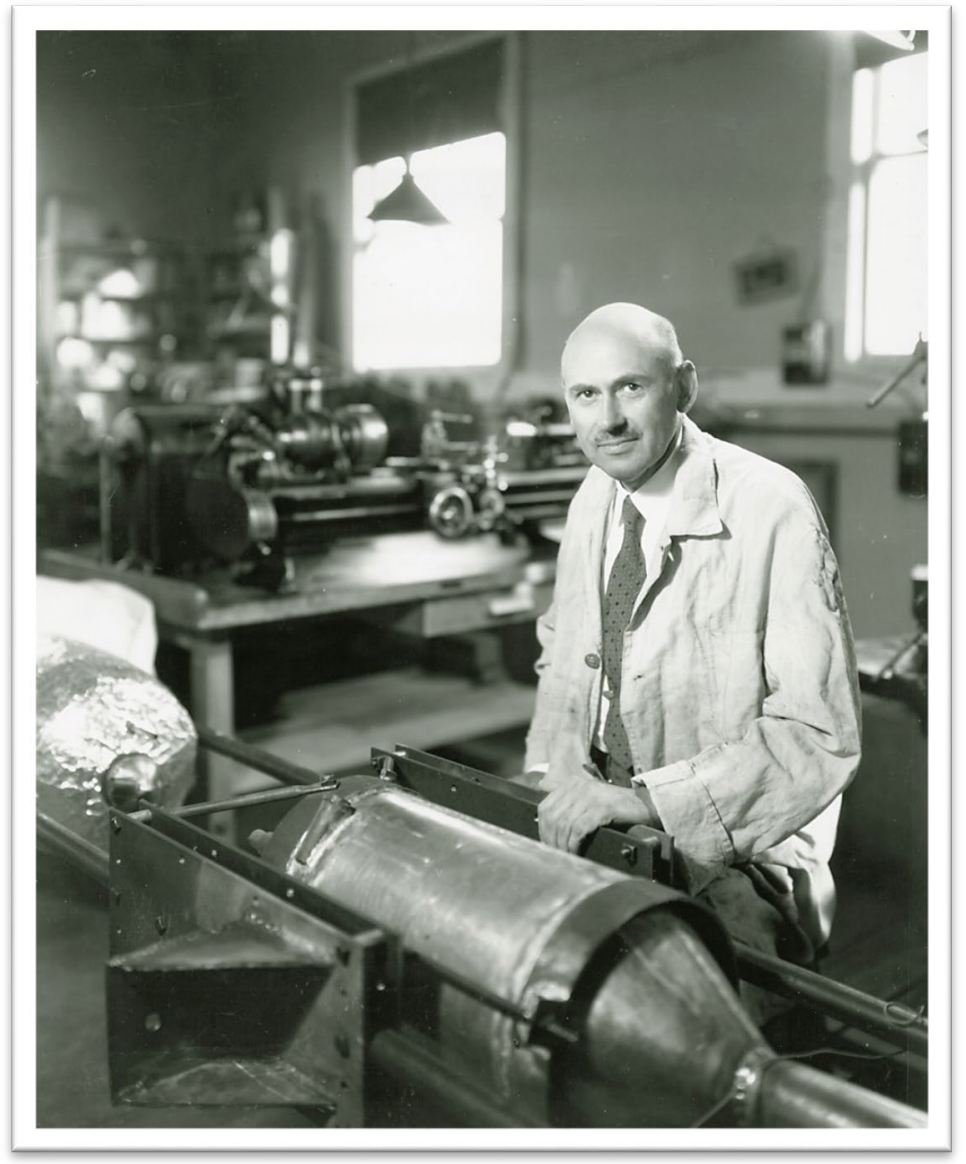




\section{.5 Ag The Postwar Years}

- The designs of the later 1940s were focused more on propelling planes and missiles than spacecraft

- Work essentially ceased on nuclear rockets in the later 1940s

- The technical problems seemed insurmountable and the military need temporarily evaporated

- But as the need for ICBMs reemerged in the early to mid 1950 s, so too did interest in nuclear rockets
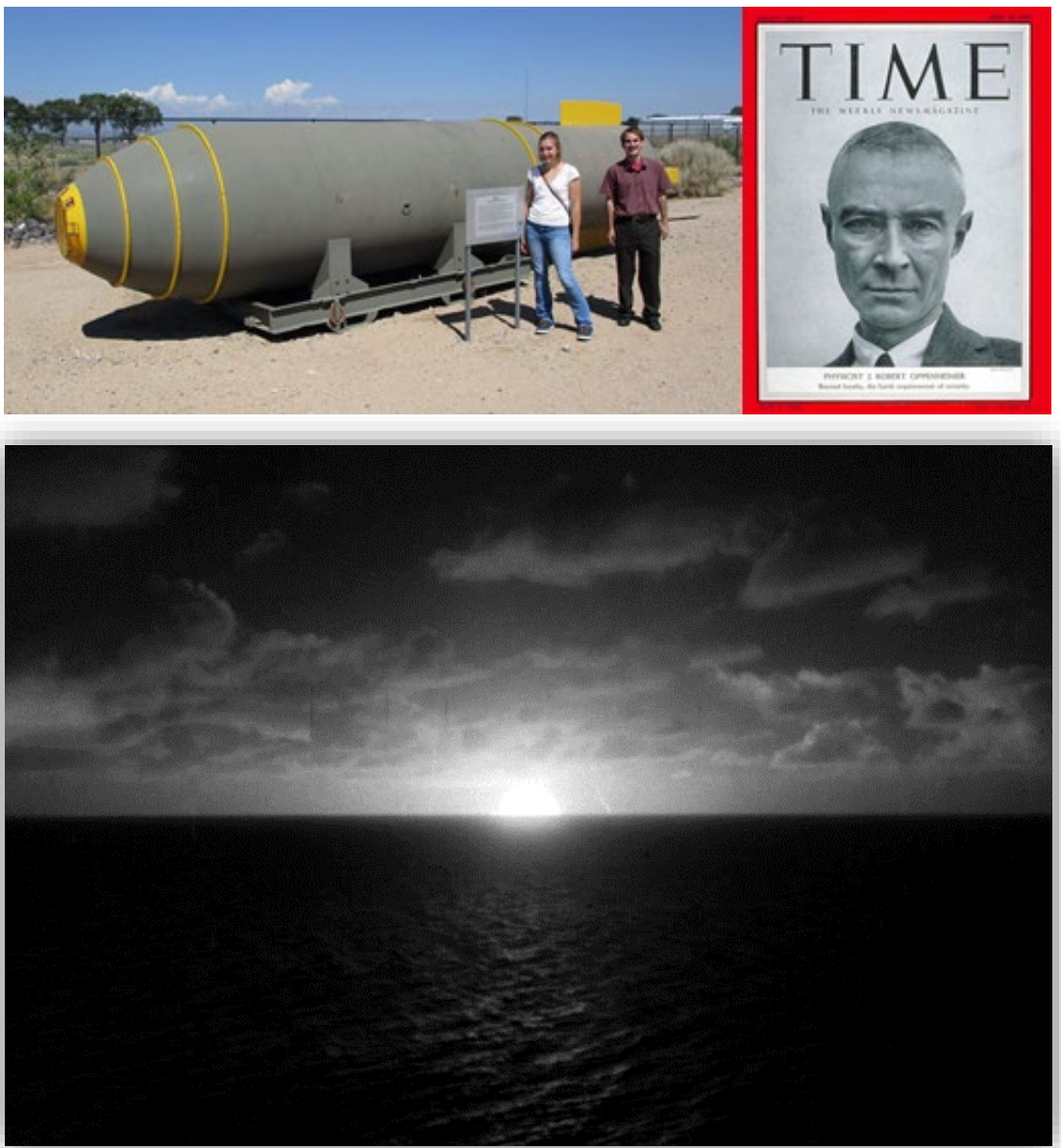
- The Soviets had a pre-war history of aggression: Poland, Finland, Romania, the Baltics, etc.

- The Berlin Blockade: June 1948 to May 1949

- The first Soviet atomic bomb was tested in late August 1949

- 1950 witnessed the end of the Chinese Civil War and the beginning of the Korean War

- A Soviet spy ring operating in the U.S. was exposed in 1950

- In the later 1950s, public fears were stoked by the Bomber Gap, the Missile Gap and Sputnik

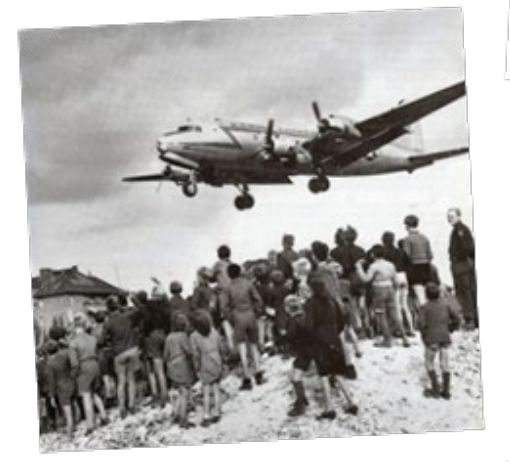

THE BFFECT OF THE SOVIET POSSESSION OF ATOMIC BOMBS ON THE SECURTY OF THE UNITED STATES

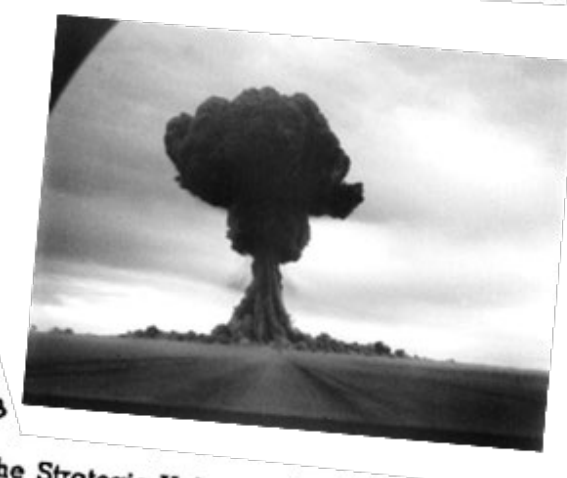

of Western Europe the USSR of the Conquest (to Cairo) prior to 1950." East

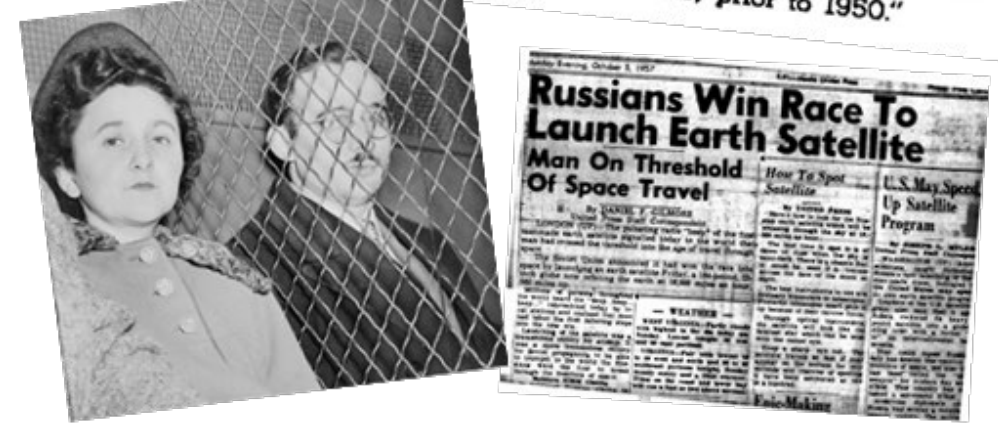


- John von Neumann, a Los Alamos alum who was advising the Air Force, became interested in nuclear rockets

- His advisory panel included the head of the LASL Reactor (K) Division, Darol Froman

- At this same time, LASL Director Norris Bradbury was interested in technically diversifying the Lab

- In October 1954, LASL and Livermore were directed to explore feasible concepts for nuclear rockets

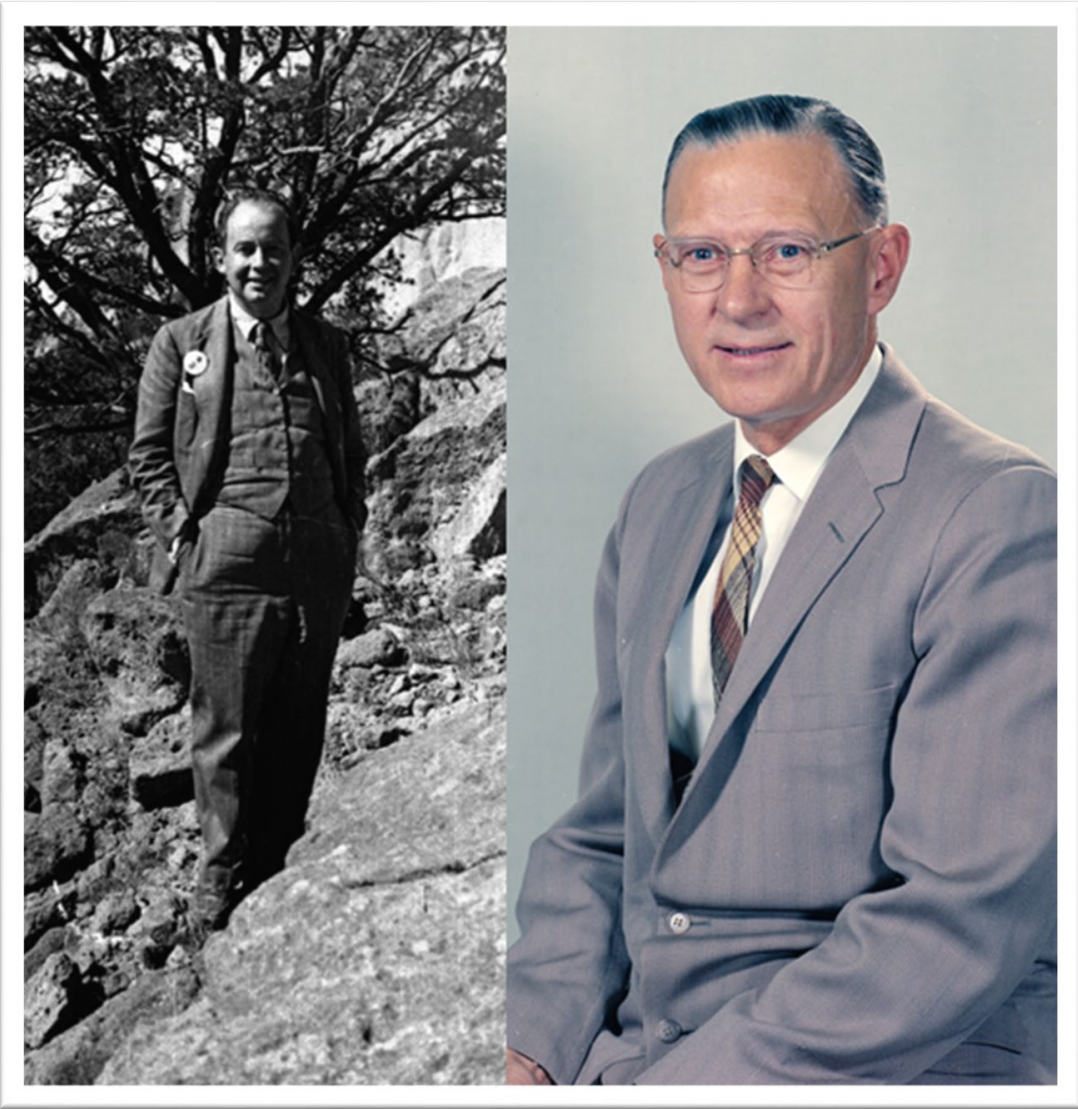


- The Los Alamos group became known as the Condor Committee

- In April 1955, Bradbury created the Nuclear Rocket Propulsion (N) Division, led by Raemer Schreiber

- Perfecting an ICBM remained the priority, but some thought was given to space exploration

- The first prototype was a 1,500 MW graphite ammonia-cooled reactor dubbed Old Black Joe

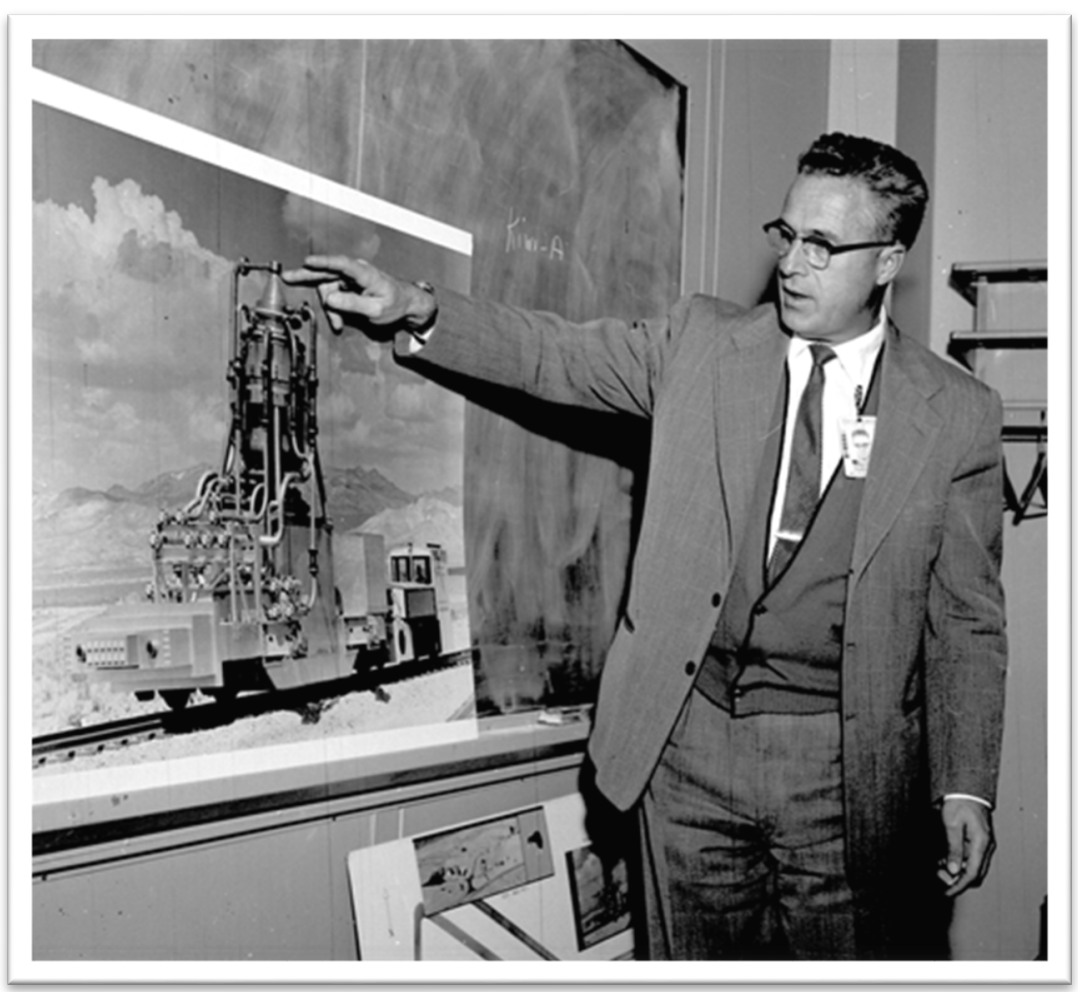




\section{AIIAASL: More Than A Weapons Lab}

\section{MAIN GATE}

- During this same period, Bradbury contemplated the Lab's future

- All the major weapons breakthroughs had already happened

- He believed nuclear weapons research would diminish

- He also thought nuclear weapons might soon become obsolete

- The 1958 testing moratorium reinforced this view

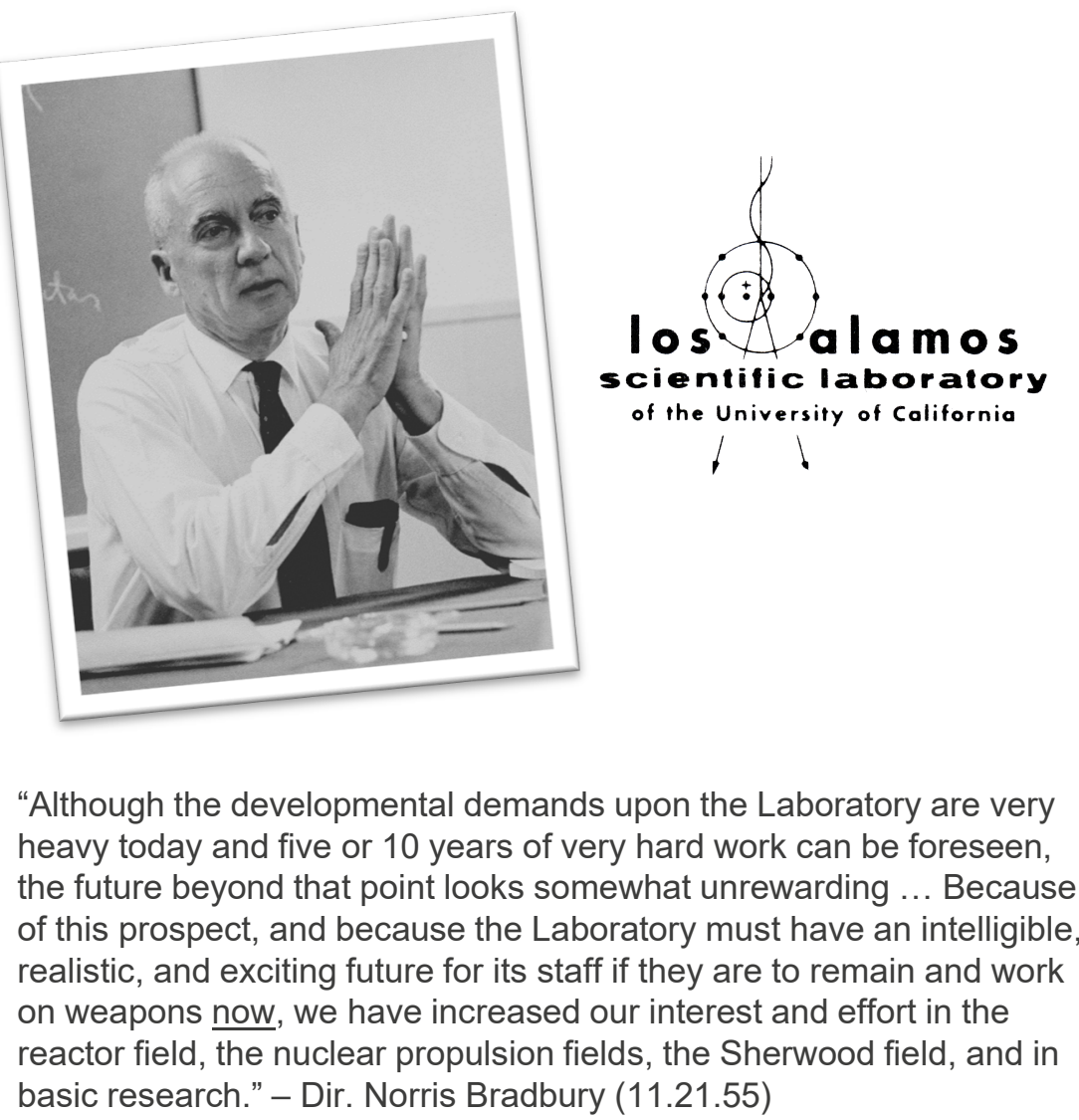

basic research." - Dir. Norris Bradbury (11.21.55) 


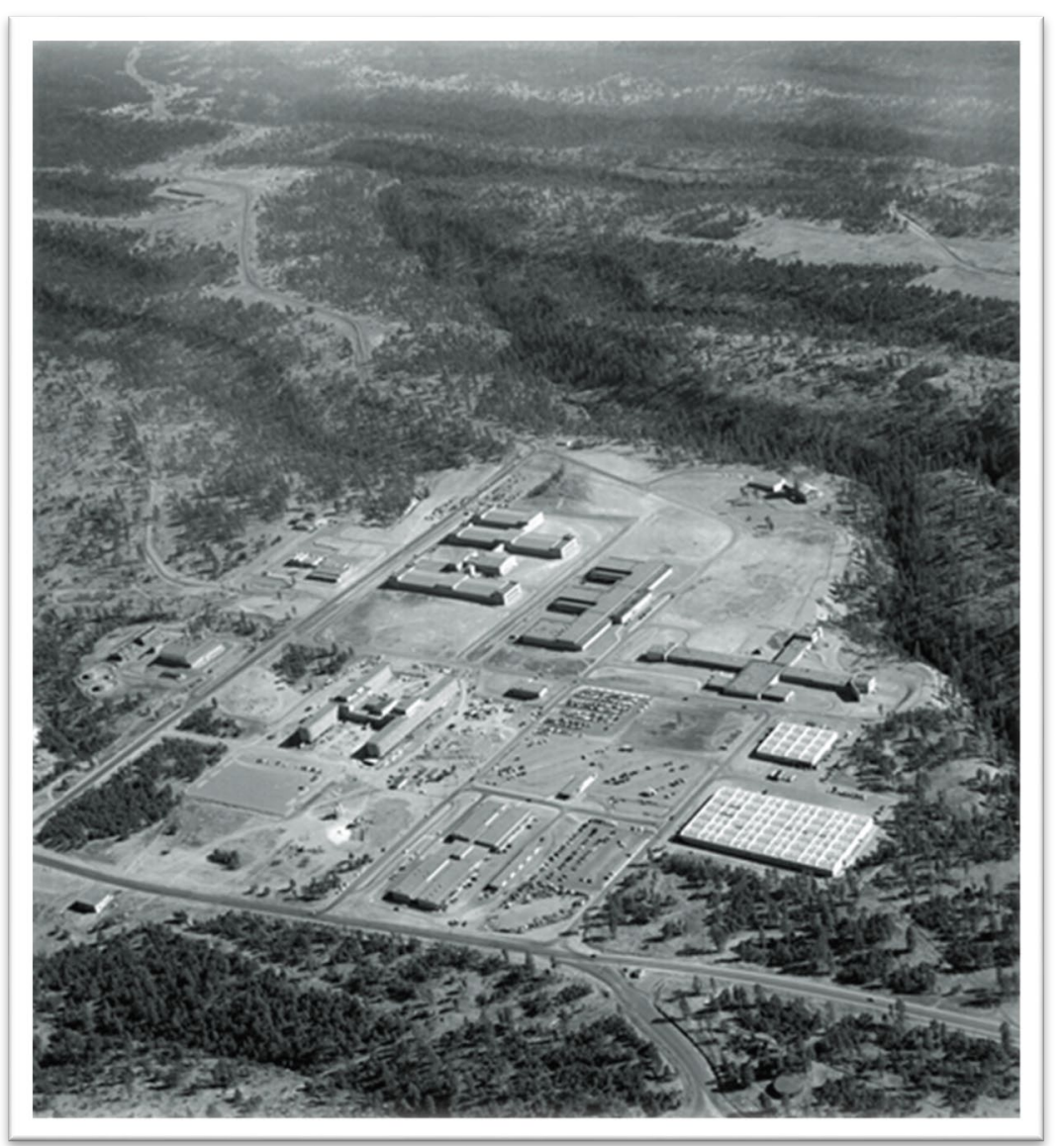

- A year after $\mathrm{N}$ Division was created, the DoD approved larger expenditures for hardware development

- But it became clear there was no need for a nuclear ICBM

- Thus, late in 1956, the program was rebranded as a space technology

- Because of this new, lower priority, only one lab would be funded to continue work: Los Alamos 


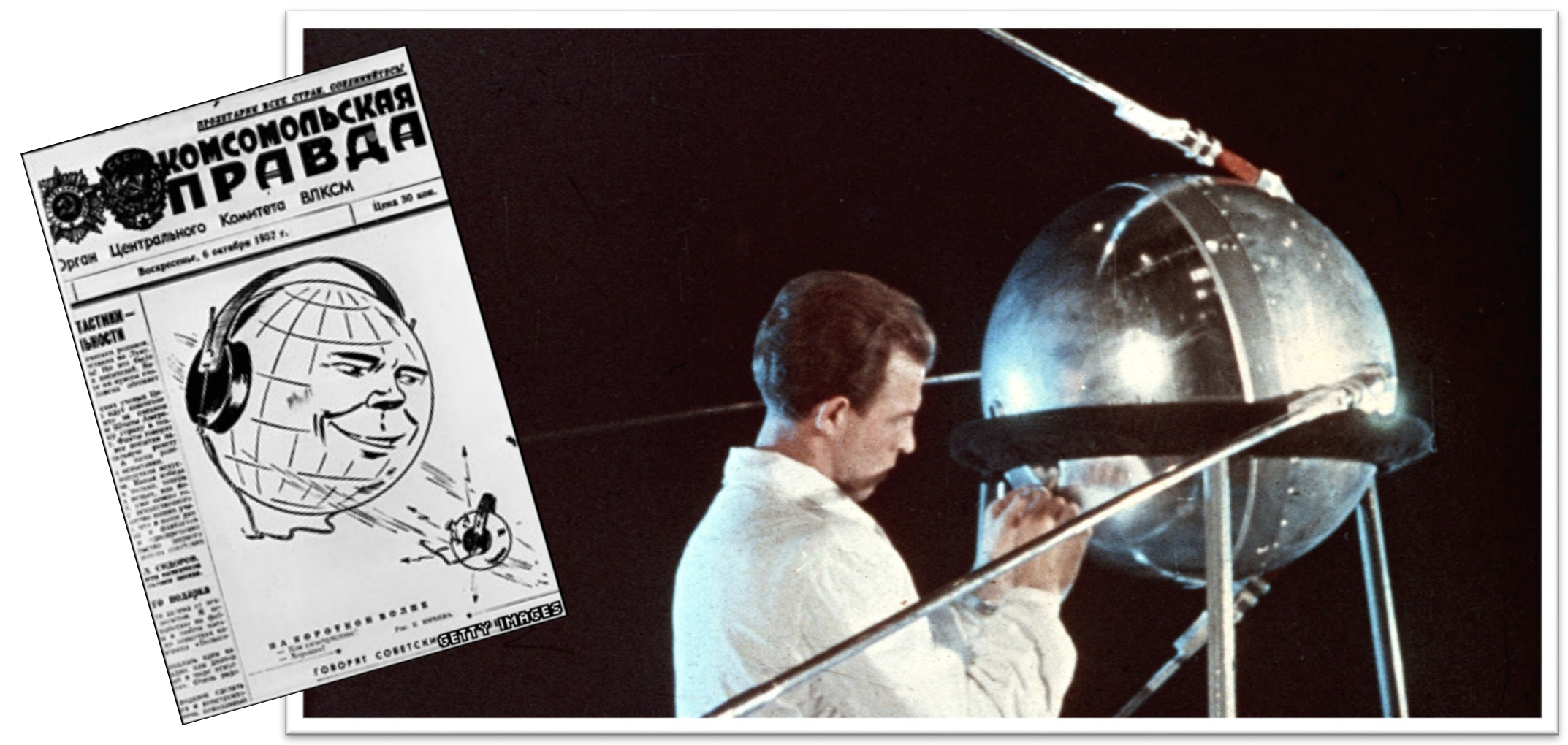

"It rescued the nuclear rocket program, although we didn't really have one." - Los Alamos Director Norris Bradbury 
- NASA inherited Rover in 1958

- Two reactors were jointly developed to demonstrate feasibility: KIWI-A and KIWI-B

- KIWI-A was largely based on Old Black Joe, but far less powerful

- It was a small, relatively simple conservative design: A hydrogenpropelled $100 \mathrm{MW}$ reactor

- KIWI-B, a 1,000 MW design, was developed alongside KIWI-A

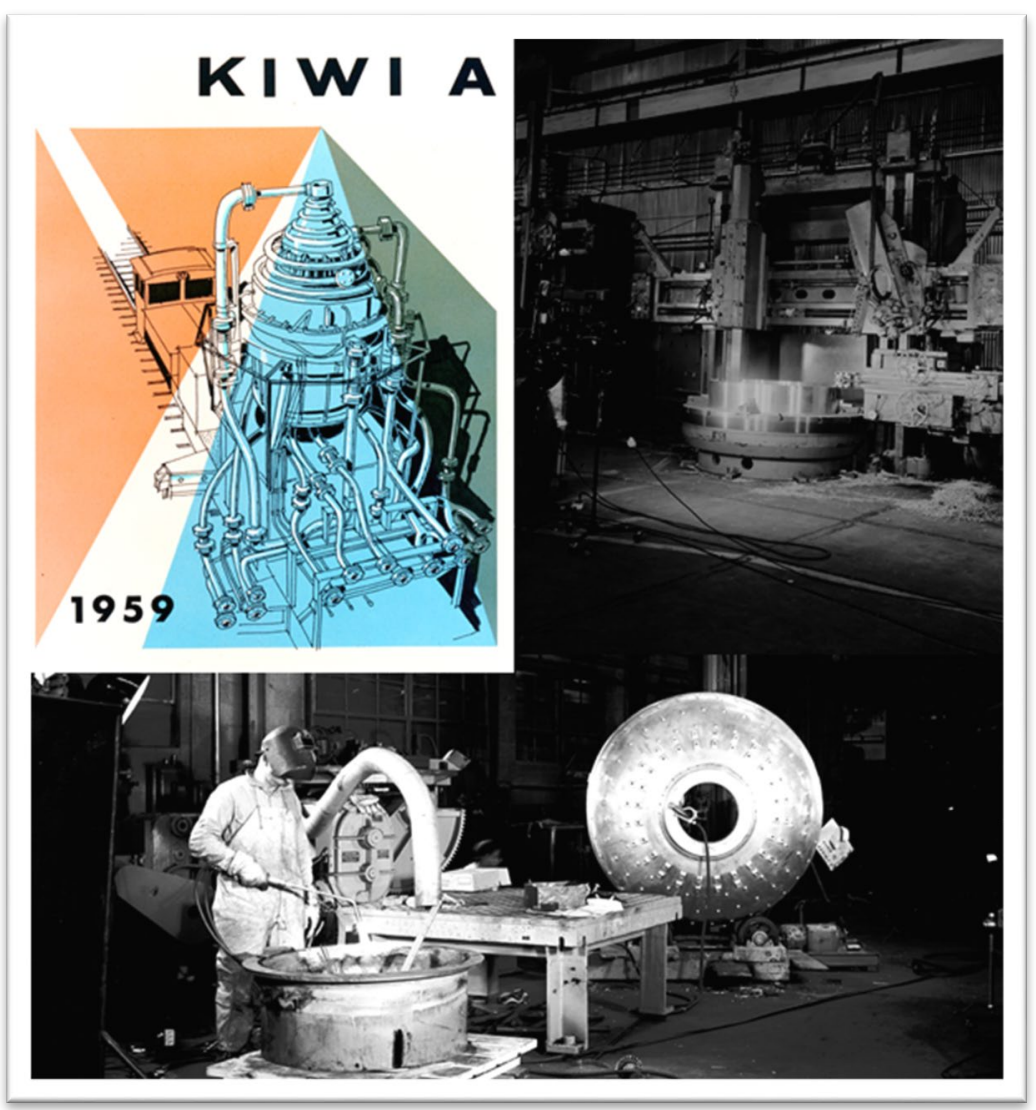




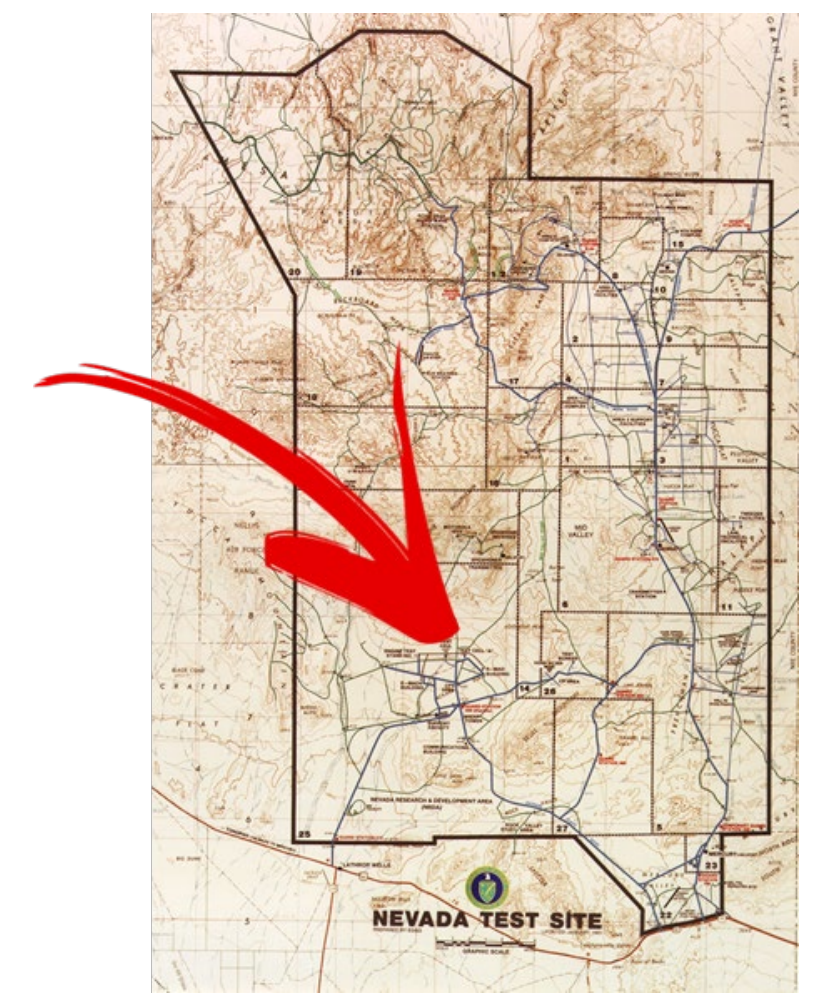

- A facility for testing Rover rockets was built at the Nevada Test Site (Area 25, Jackass Flats)

- It was called the Nuclear Rocket Development Station (NRDS)

- R-MAD: Reactor Maintenance, Assembly, and Disassembly

- Test reactors were sent from R-MAD to Test Cell A two miles away aboard a remote controlled train

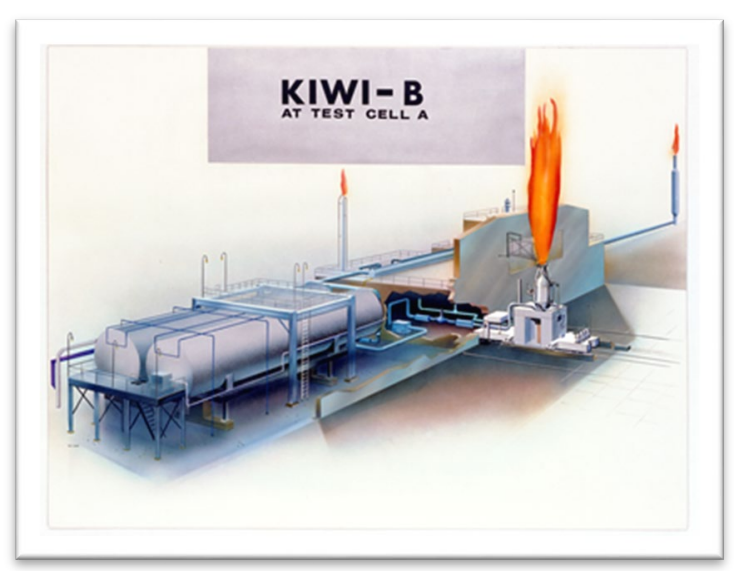


- The test facility was completed in 1958 and the first full-scale KIWI-A test occurred July 1, 1959

- SUCCESS: Although the hydrogen damaged graphite components, KIWI-A ran at 70 MW for five minutes

- However, KIWI-A was a relatively simple prototype

- KIWI-B was 10 times as powerful and jointly under development

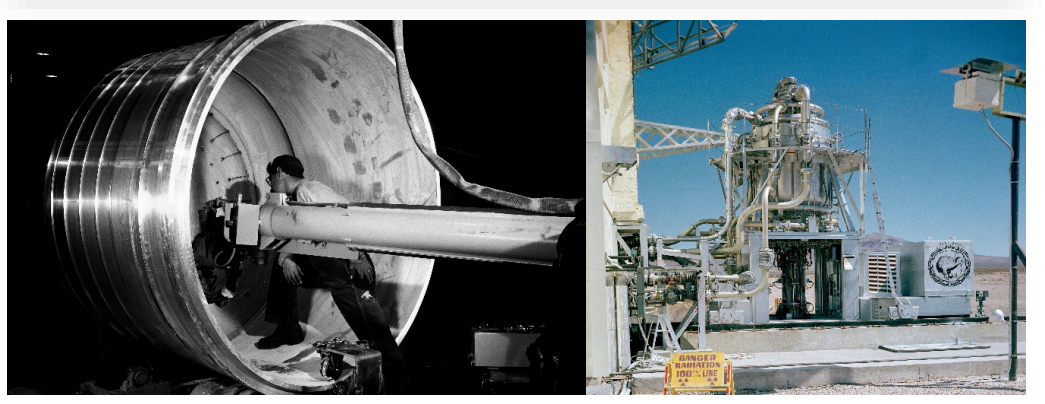


- Budget problems began to plague the program in 1959

- The most significant technical challenge was protecting the graphite from the hydrogen

- Various methods were employed and tested in 1960

- KIWI-A was rebuilt and tested July 8, 1960

- KIWI-A3, a version of KIWI-A with several refinements, was tested October 19th

- Again, fuel elements were heavily damaged, but erosion in the A3 was greatly reduced

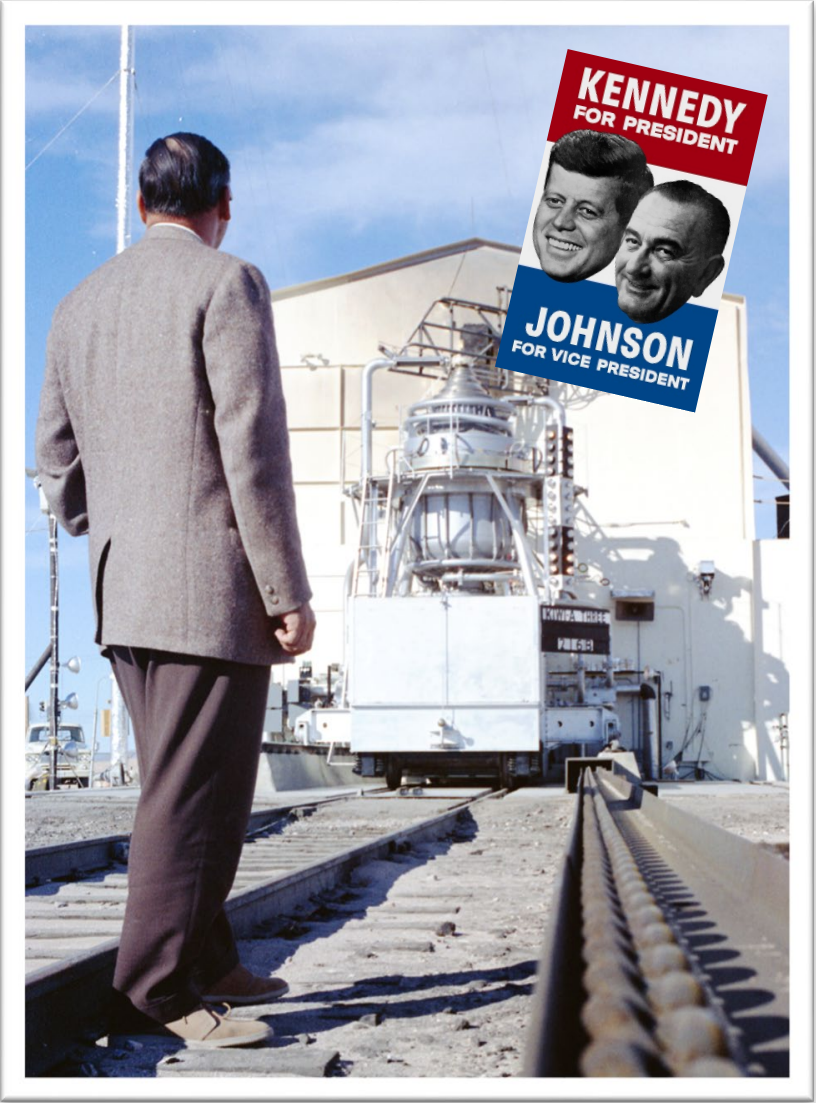




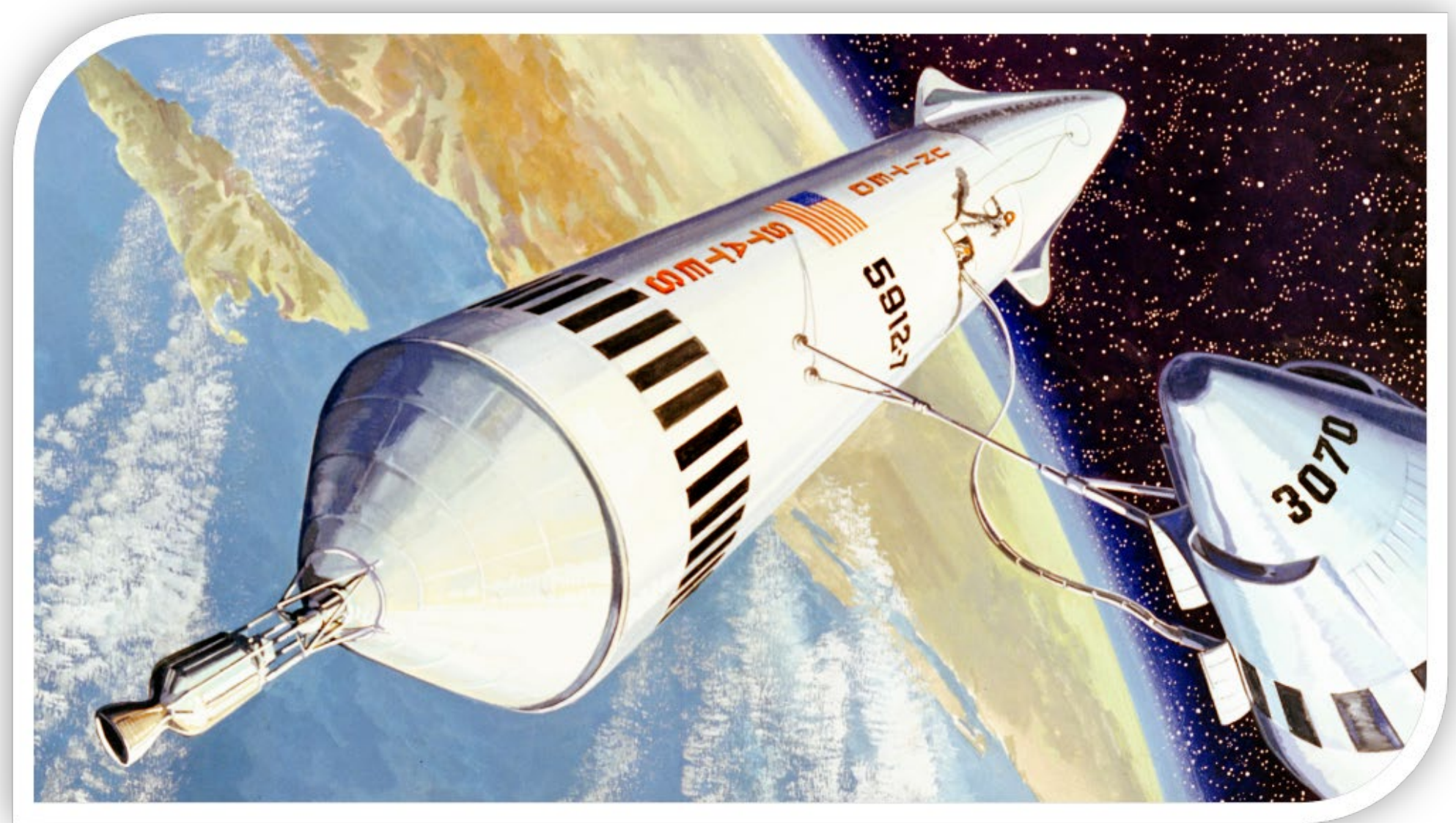


- May 1, 1960: A U.S. spy plane was shot down over the Soviet Union

- April 12, 1961: Yuri Gagarin became the first person to visit outer space

- Only five days later, the Bay of Pigs Invasion of Cuba unfolded ... and promptly failed

- Construction on the Berlin Wall began in August 1961

- The Soviets abrogated the testing moratorium on Sept. 1, 1961

- Sept. 15, 1961: The U.S. resumed testing

- The Tsar Bomba was tested Oct. 30, 1961

- October 1962: The Cuban Missile Crisis

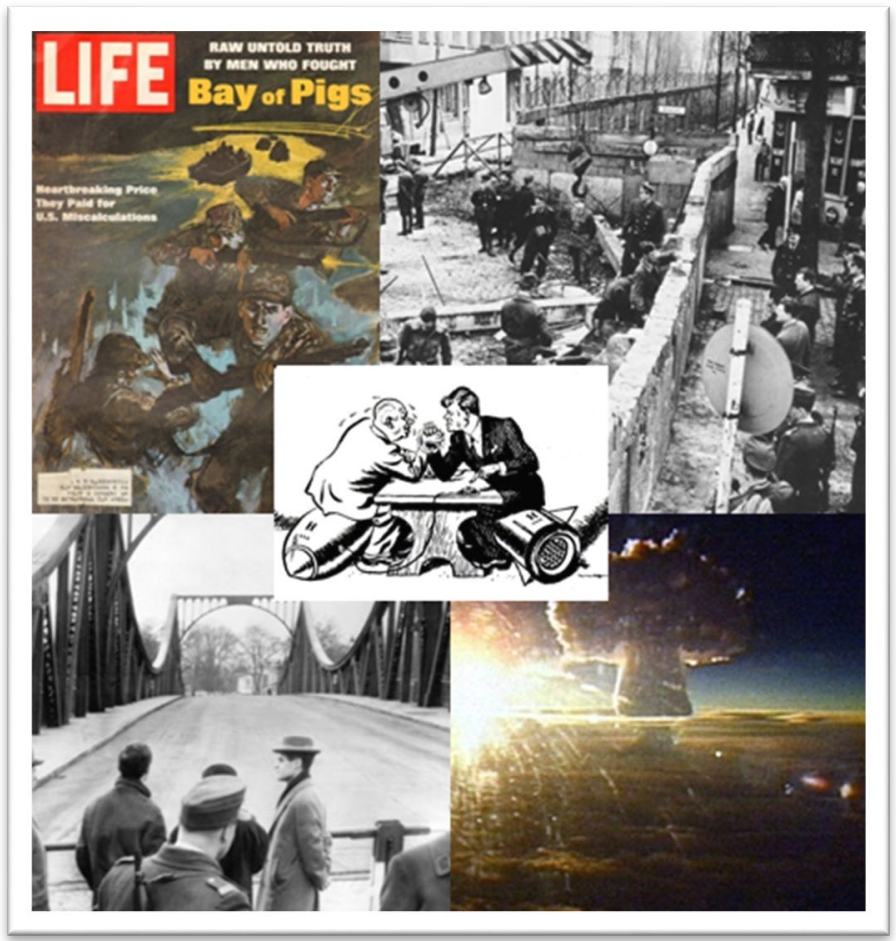


- KIWI-B represented a major leap forward from KIWI-A

- Still, it remained a developmental 1,000 MW reactor; another step toward a 10,000 MW design

- The B-1 and B-2 reactors were variations on the same, basic $B$ reactor design

- The B-4 was a revolutionary, compact and efficient design

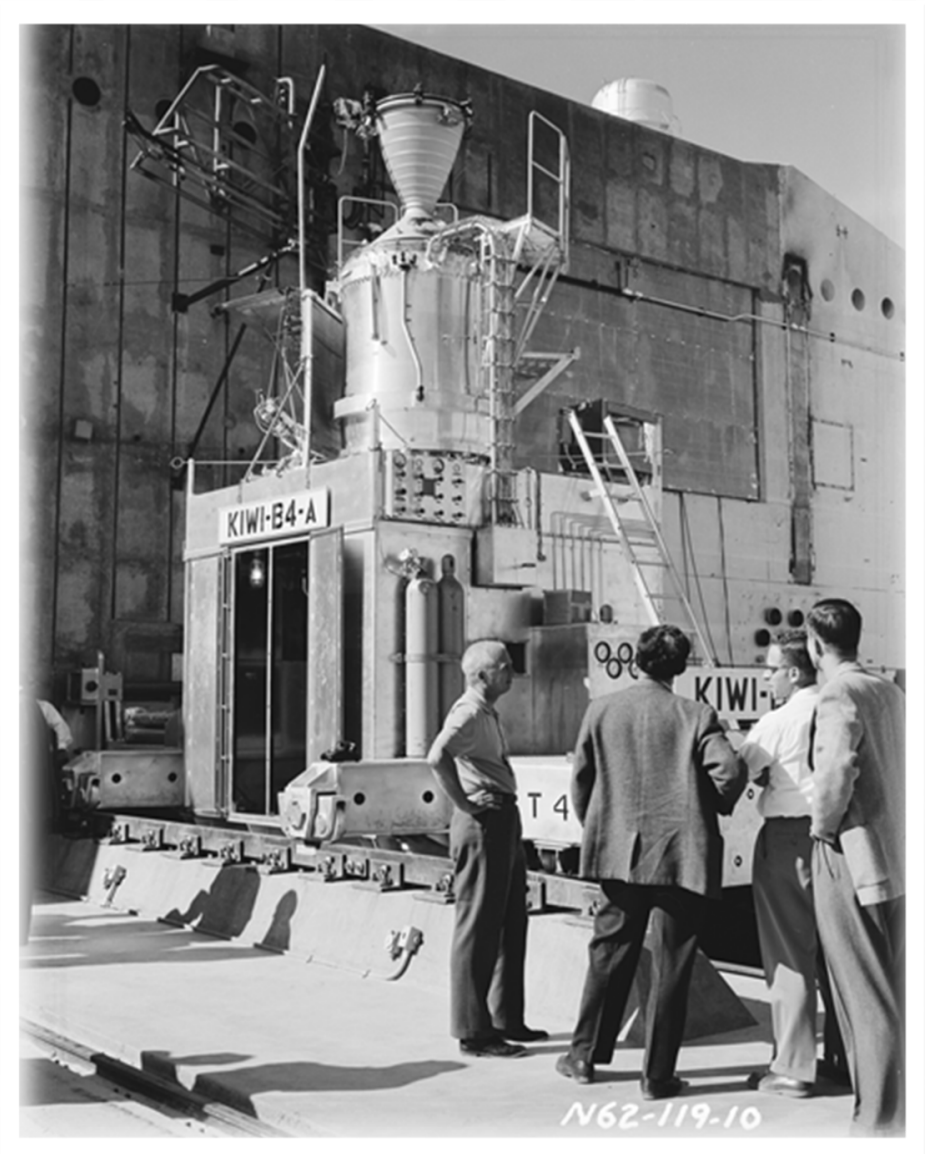


- The B-1 program moved forward because it was the furthest along in development

- Multiple accidents occurred leading up to the December 1961 test

- The reactor was tested at 300 MW with gaseous hydrogen; the test was marginally successful

- In addition to technical problems, the resumption of nuclear testing affected budgetary priorities

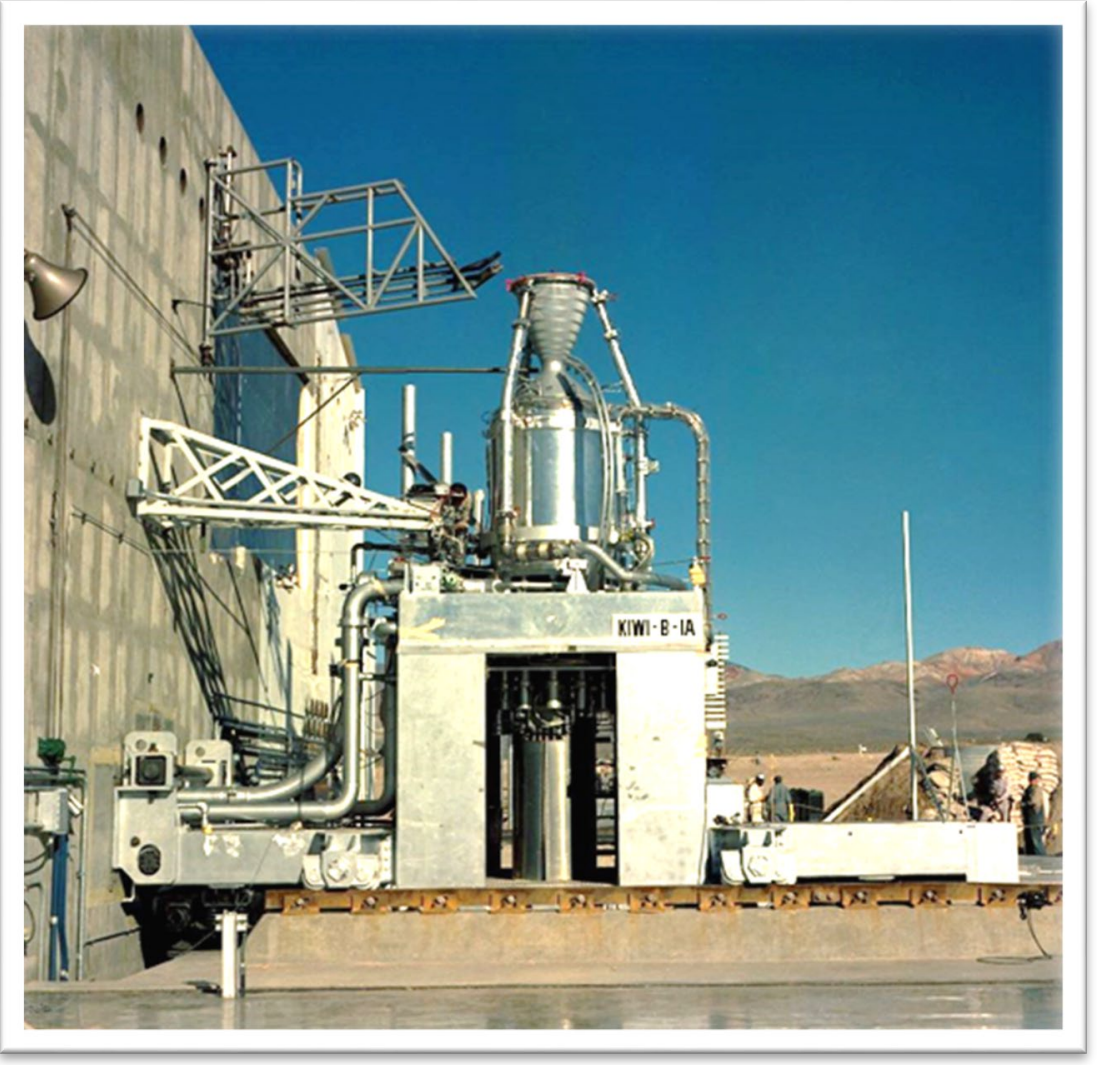




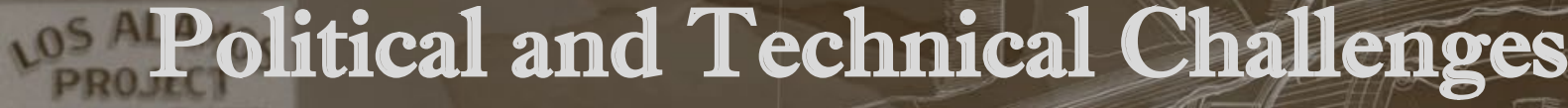

- Despite support from powerful patrons in the Democratic Party, many regarded the nuclear rocket as impractical

- But the successes of the Soviet space program helped keep Rover alive

- On September 12, 1962, President Kennedy publicly announced the goal of a lunar mission

- Nuclear rockets were intended to support missions beyond the moon and push the country far ahead in the space race 
- KIWI-B-4 emerged as the preferred design, but B-1 variants continued to serve in order to advance the program

- Unlike other designs, the B-4 was scalable: if it would work at $1,000 \mathrm{MW}$, it could likely be made to work at 5,000

- On November 30, 1962, KIWI-B4A was tested in Nevada

- The test appeared to be another "failure," but the president still favored an aggressive approach

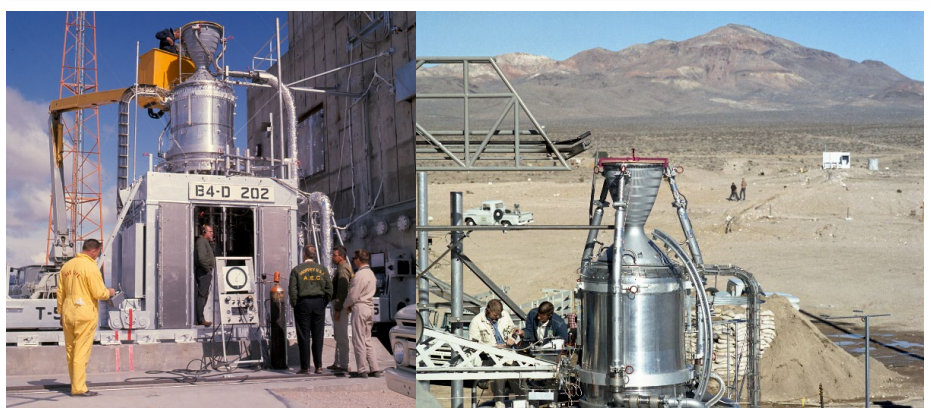



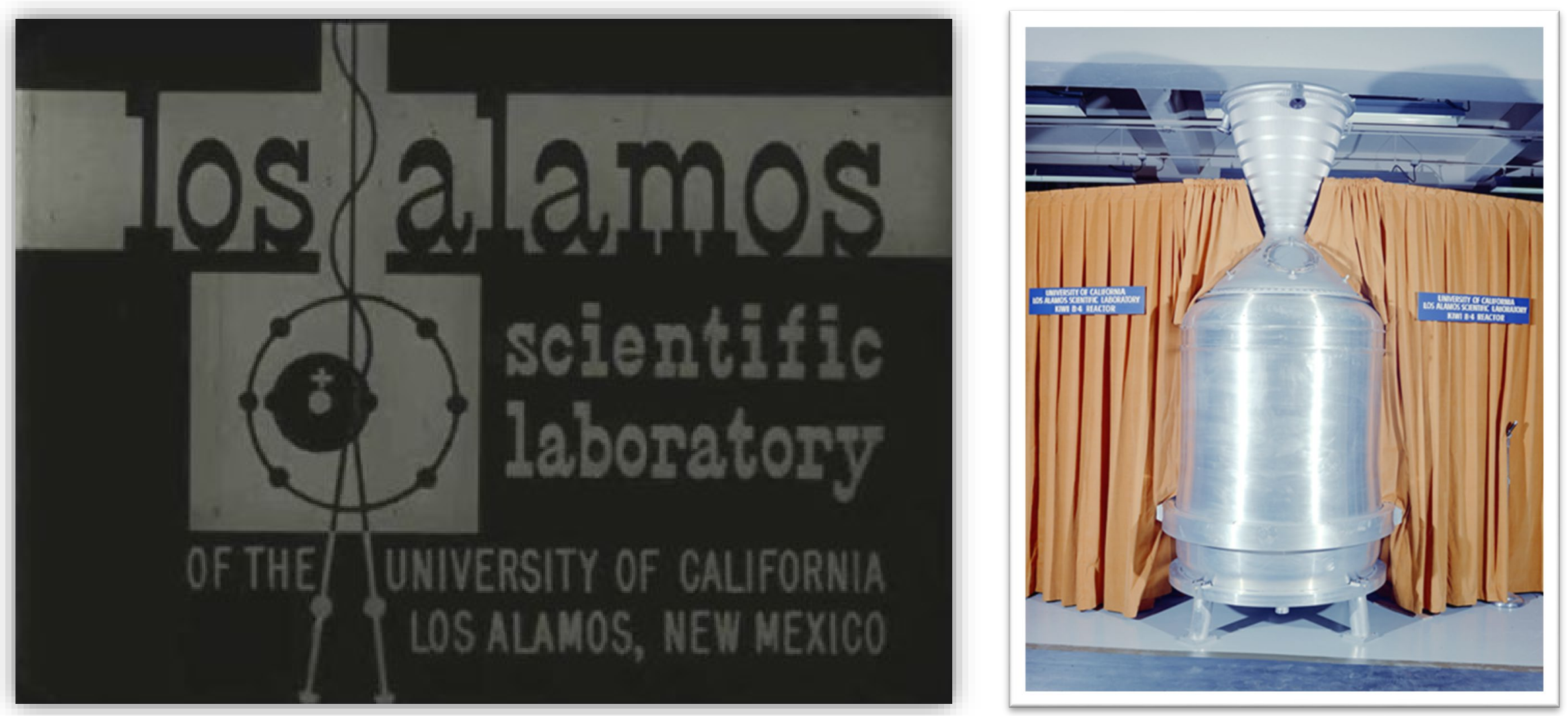
- In May 1963, KIWI-B4-A was tested once again to confirm vibration as the main problem

- KIWI-B4-B incorporated improvements and was successfully tested in August

- Two more KIWI reactors were built and tested: the B4-D and B4-E

- B4-D was successfully hot tested at full power in May 1964

- In August, the B4-E ran for eight minutes at $900 \mathrm{MW}$ ! 


\section{.05 AlKIWI-A and KIWI-B-4 Comparison}

\section{MAIN GATE}
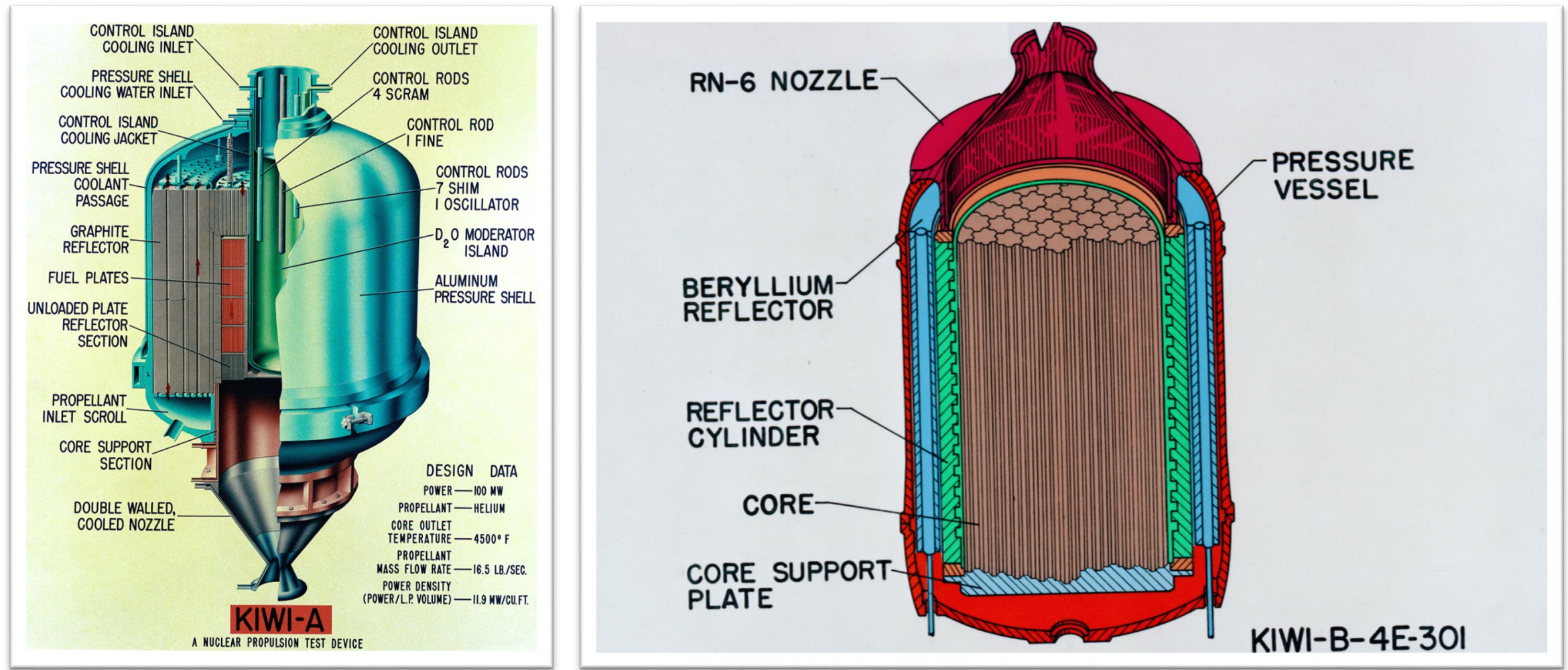
- The flightworthy reactor engine was dubbed NERVA: Nuclear Engine for Rocket Vehicle Application

- Early on, it was hoped that flight testing would begin in 1967

- But as costs escalated and competition from the Apollo Program mounted, President Johnson terminated the flight program in early 1964

- Rover became an R\&D project; a program without a specific mission

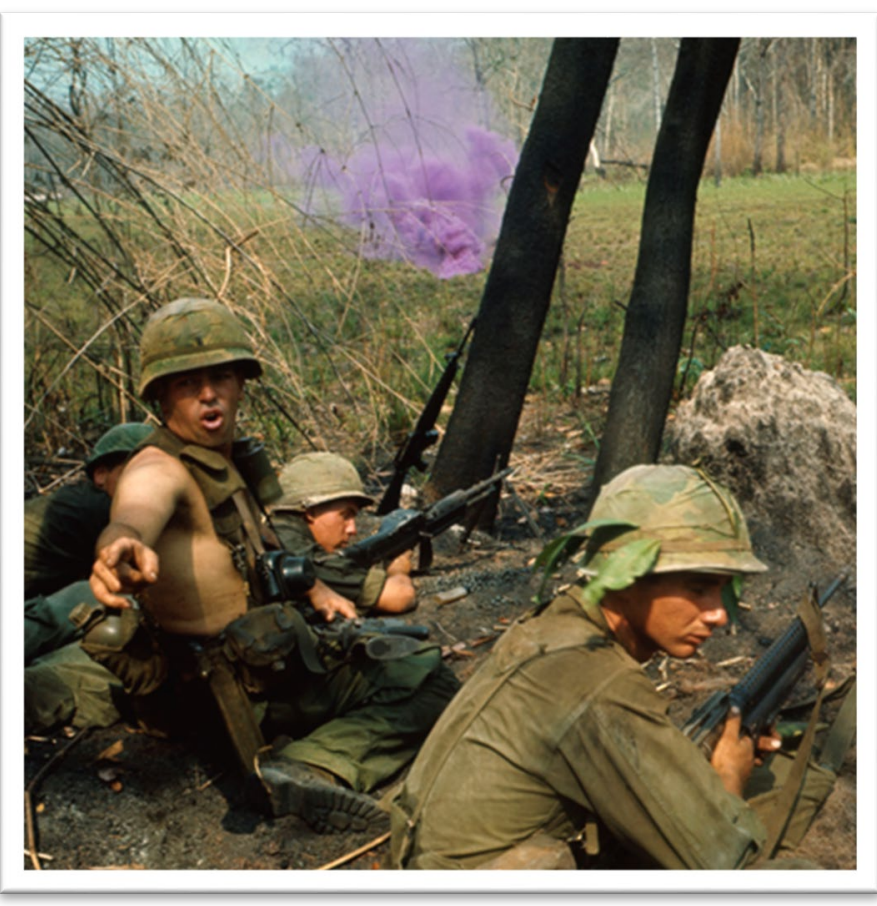

Funding the Vietnam War and the Great Society emerged as top priorities of the mid-1960s as interest in exploration beyond the moon waned. 
- The Transient Nuclear Test (TNT) was the last KIWI test

- A KIWI-B reactor was intentionally destroyed Jan. 12, 1965

- How can nuclear rockets be safely disposed?

- What are the consequences of a nuclear accident involving a nuclear rocket?

- A large percentage of the core material was never accounted for (so don't pick up anything at the site!)

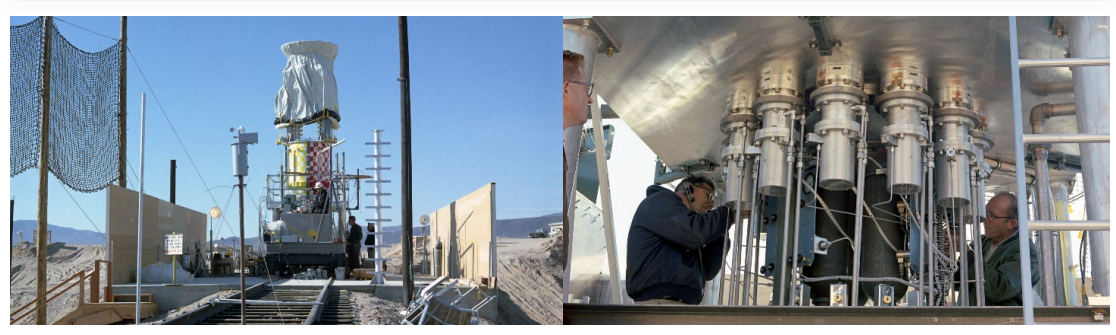


- The Phoebus series reactors were intended as prototype engines for flight testing

- On June 25, 1965, Phoebus-1A ran for 10.5 minutes at full power $(1,090$ MW)

- Its successor, $1 \mathrm{~B}$, ran at $1,500 \mathrm{MW}$ for 30 minutes in February 1967

- Phoebus-2A reached 4,080 MW during a 12-minute run on June 26 , 1968

- 2A (designed for 5,000 MW) was the most powerful reactor ever built!

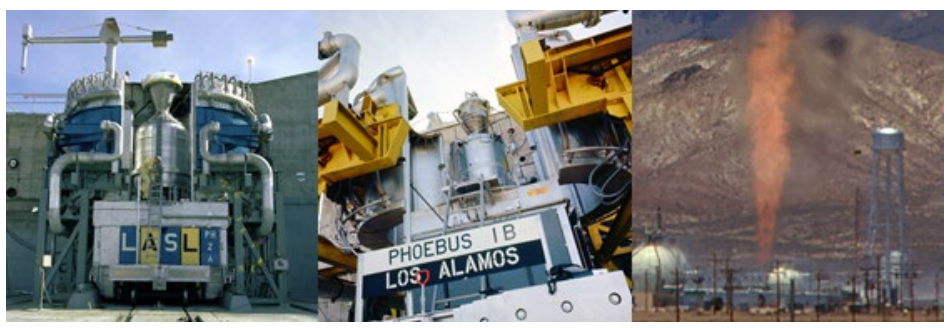




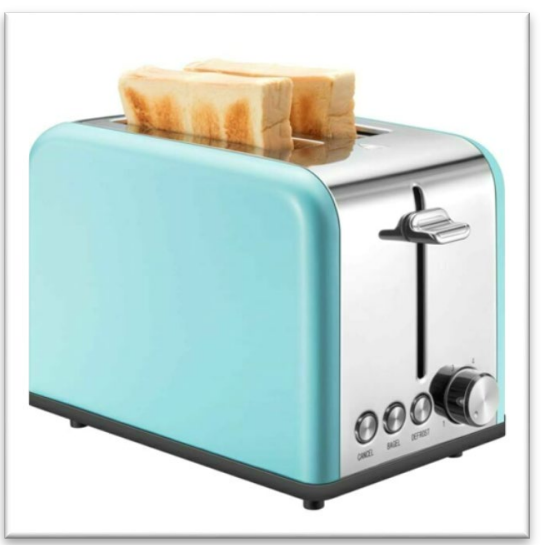

You could power 8.5 million toasters! (But what would you do with all that toast?)

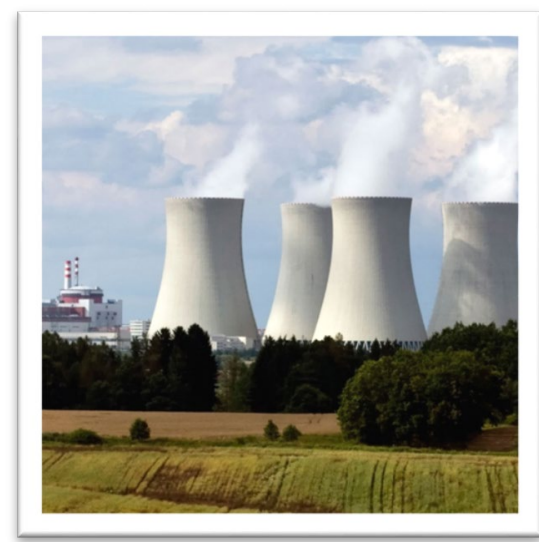

The Phoebus-2A is at least as powerful as any modern reactor, but far more compact!

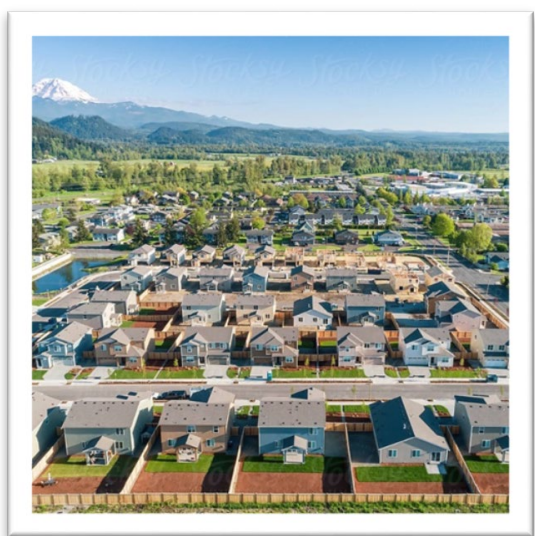

You could provide power for $\sim 250,000$ homes for the duration of the test!

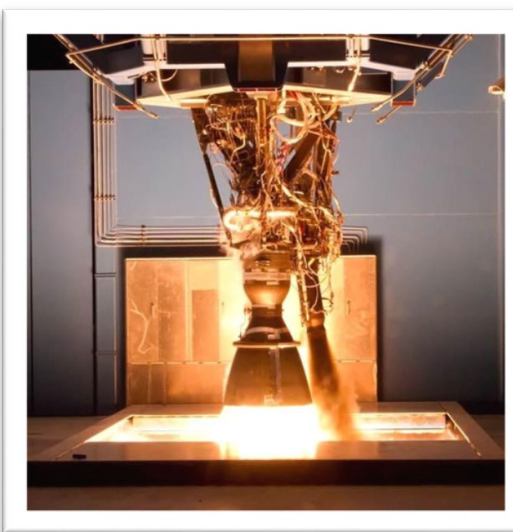

The Phoebus-2A is $\sim 30 \%$ more powerful than a modern SpaceX Merlin 1D engine! 


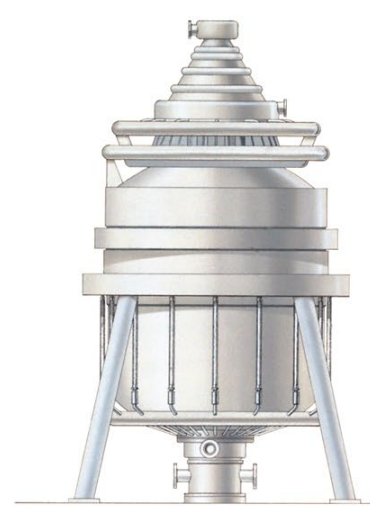

KIWI A
$198-60$
100 MEGAWATS
O LBS. THRUST

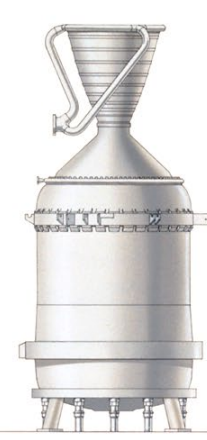

$K I W 1$
$1966-64$

1000 MEGAWATTS
50.000 LBS. THRUST

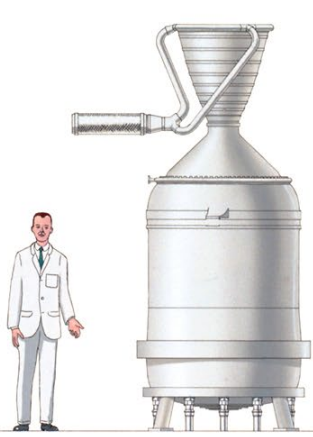

PHOEBUS 1 $1000 \& 1500$ MEGAWATTS
50.000 LBS. THPUST

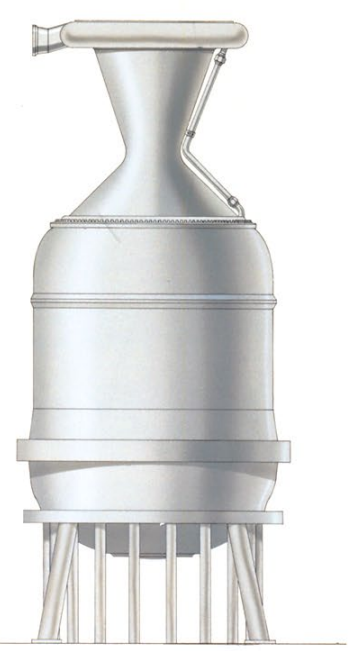

PHOEBUS 2

5000 MEGAWATTS

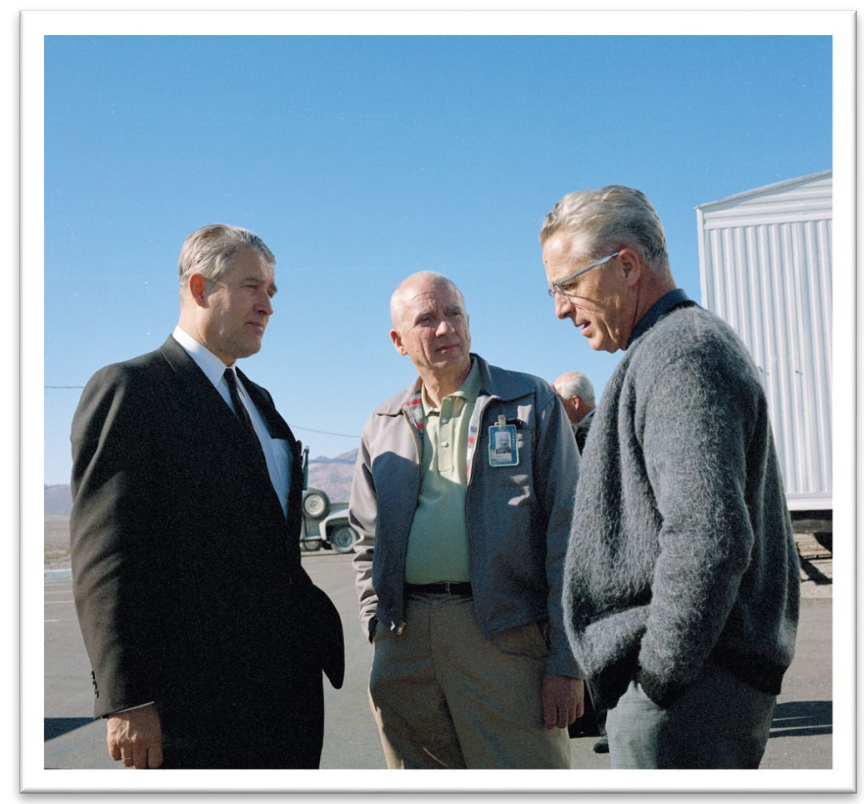

Wernher von Braun, Norris Bradbury and Raemer Schreiber visit the Nevada Test Site in 1967. 
- The Phoebus series demonstrated the feasibility of nuclear rockets for missions beyond the moon

- However, they were the last, large LASL nuclear rockets

- Pewee was developed to test components for larger reactors

- In late 1968, Pewee was successfully tested: The peak exit temperature of $2,750 \mathrm{~K}$ (nearly 4,500 F) was a Rover record!

- Pewee could be adapted for orbital and moon missions ... but wasn't

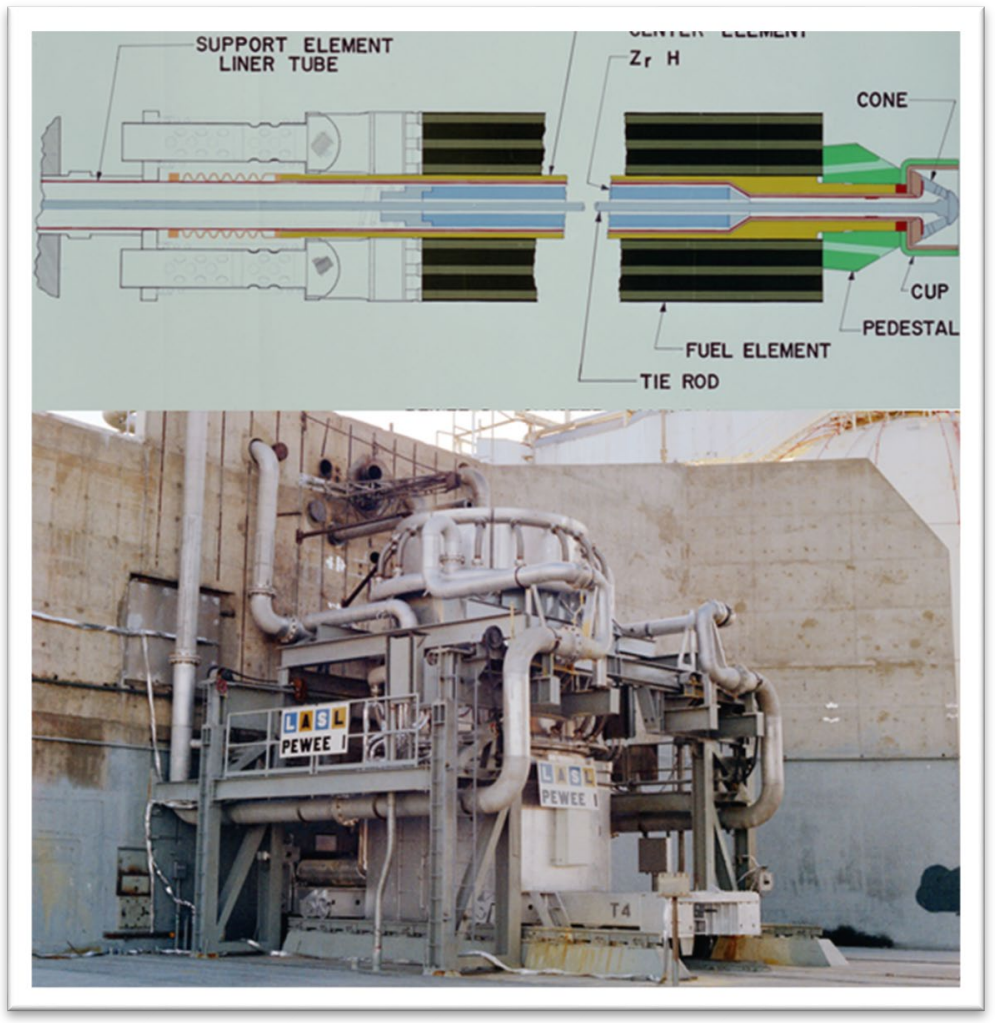



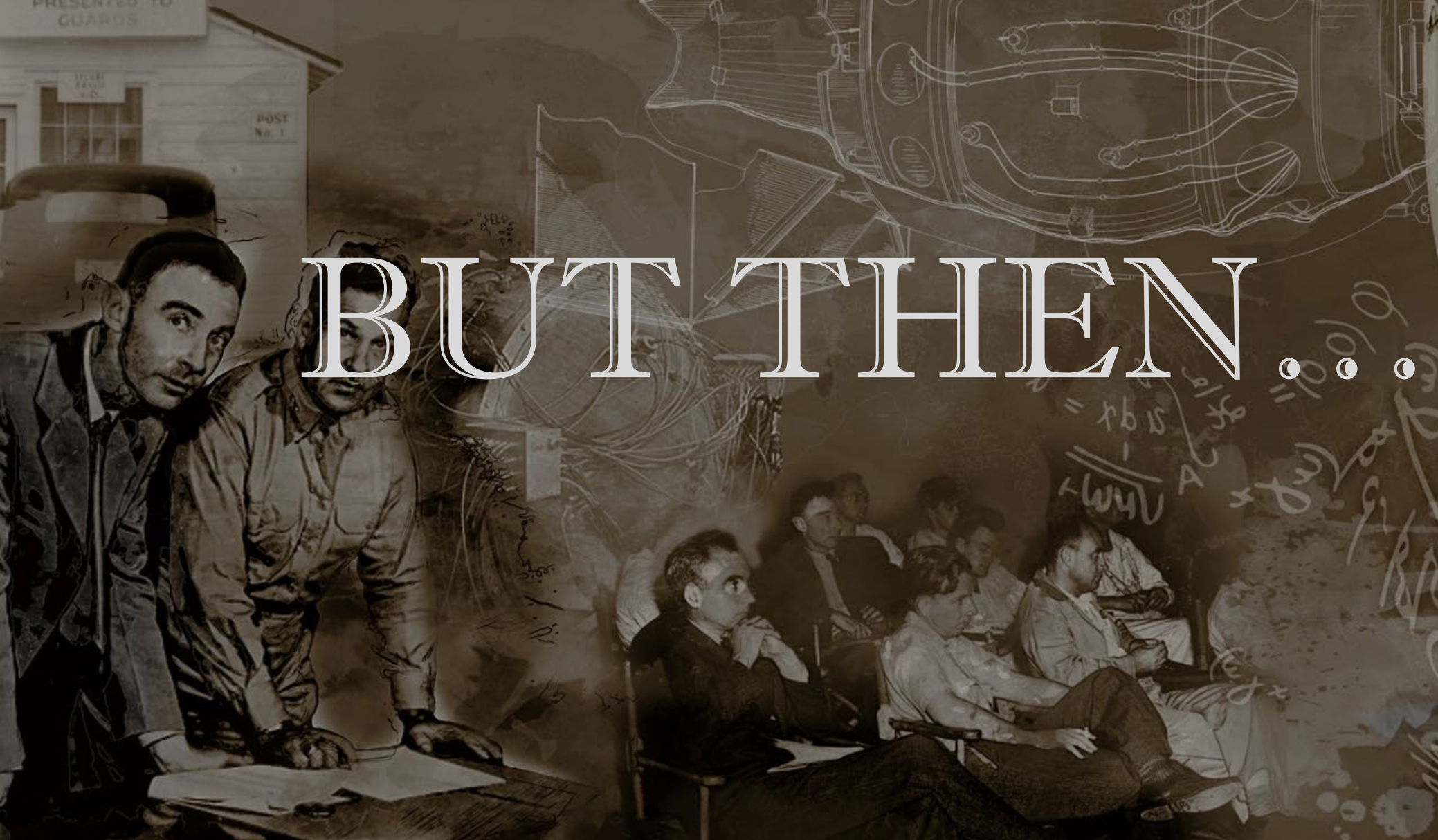

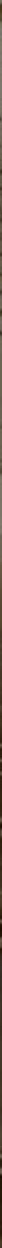
- Small though Pewee was, it was 10 times more powerful than the Nuclear Furnace (NF-1)

- NF-1 provided a reusable structure to test reactor core assemblies

- This feature was proven feasible in the only NF-1 test

- The NF-1 test series, conducted in the late spring of 1972 , produced impressive results

- Unfortunately...

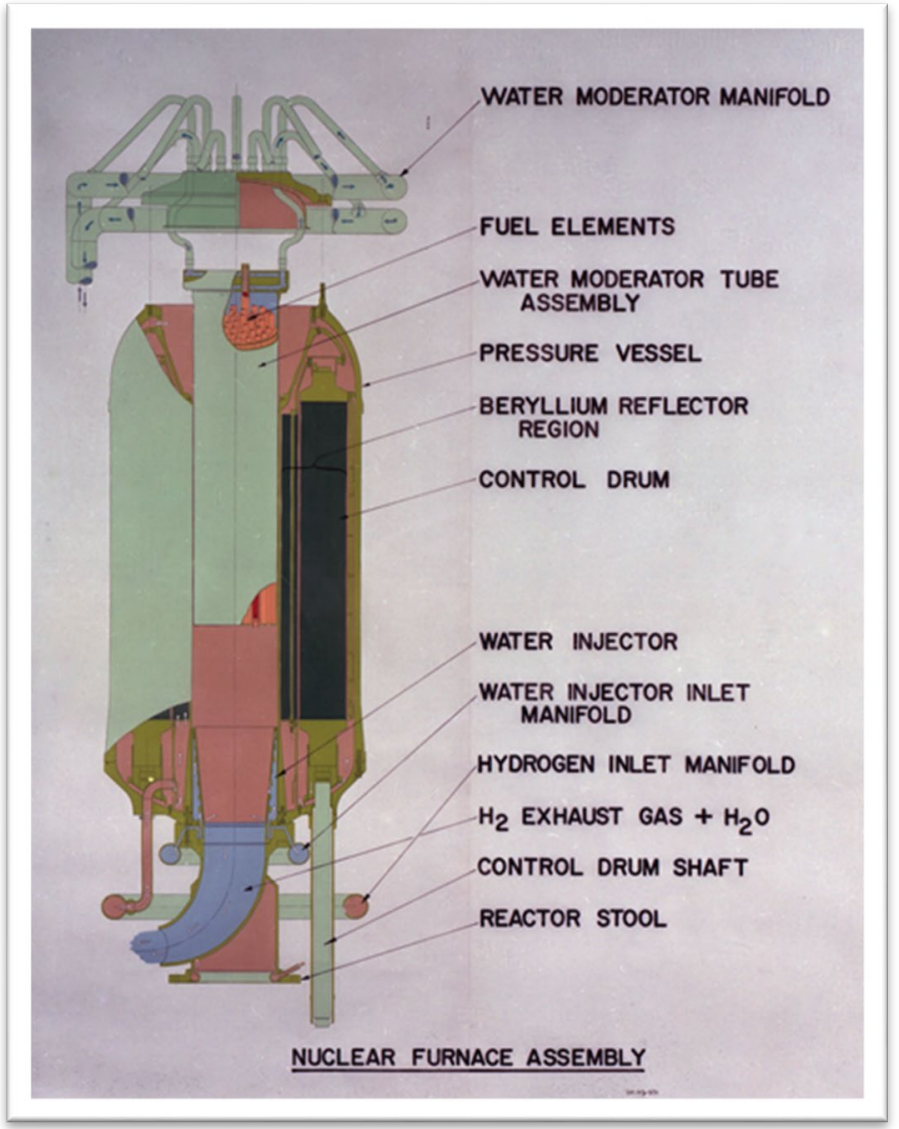




\section{.05 A A The end?}

- The nuclear rocket worked! ... But it had lacked a specific mission since early 1964

- Even during the Kennedy Administration, officials feared a costly space race with the Soviets

- In the early 1970s, a manned mission to Mars was reconsidered

- The mission was deemed too expensive and dropped ... along with Rover

- Rover produced reactors ready for

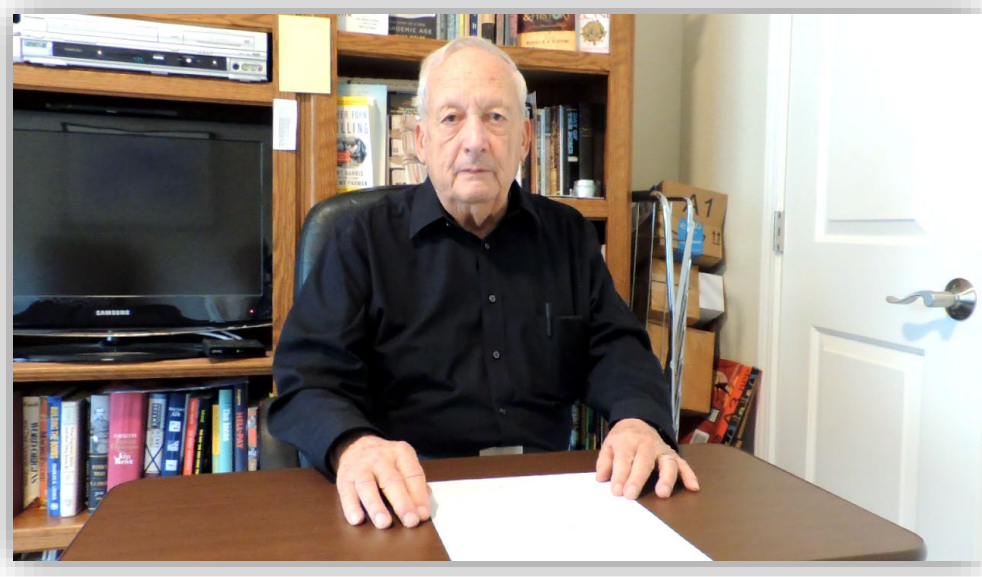

On January 9, 1973, the cancellation of the Rover program was announced at LASL. flight testing, but national priorities had changed 


\section{Pous What did Rover achieve?}

- The Saturn Project borrowed Rover technology

- Rover produced new materials, handling techniques and compact reactor designs

- Rover records included: 4,080 MW of power (Phoebus-2A), 2,750 K fuel temperatures (Pewee) and $930 \mathrm{kN}$ of thrust (Phoebus-2A)!

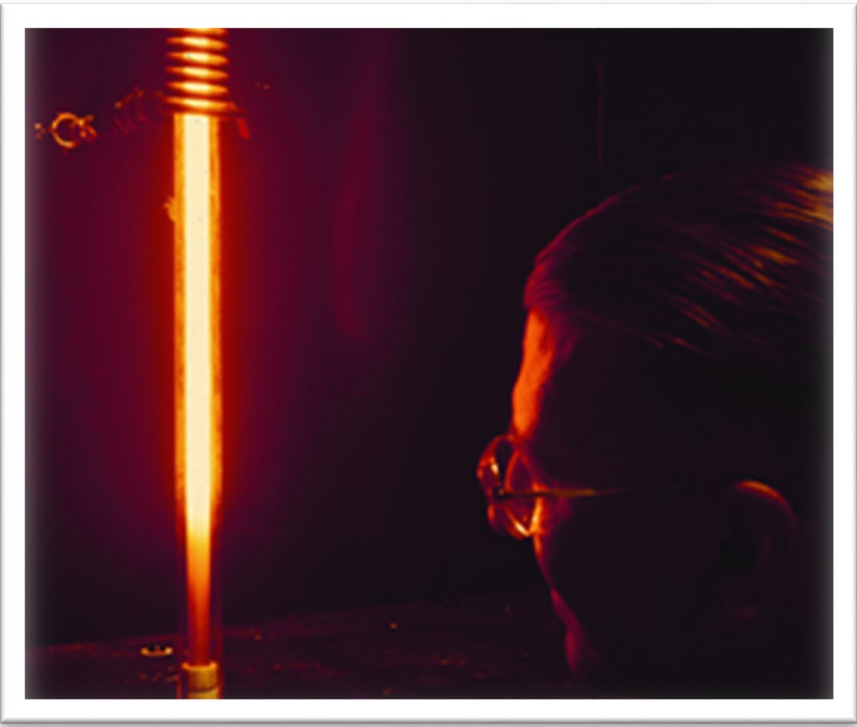

- Rover significantly advanced our understanding of several materials most notably graphite and carbon

- The heat pipe was the most significant of many spinoff technologies

"The nuclear rocket was not a dead-end project. What was achieved was utterly remarkable." - James Dewar 
- James Dewar, Project Rover: A Study of the Nuclear Rocket Development Program, 1953-1963

- James Dewar, To the End of the Solar System: The Story of the Nuclear Rocket

- J.L. Finseth, "Overview of Rover Engine Tests: Final Report"

- Brian Fishbine et. al, "Nuclear Rockets: To Mars and Beyond, in National Security Science Magazine” (Issue 1, 2011)

- Daniel R. Koenig, "Experience Gained from the Space Nuclear Rocket Program" (Rover)

- Clayton W. Watson, "Nuclear Rockets: High-Performance Propulsion for Mars"

- And hundreds of cubic feet of records in The National Security Research Center! 